Florida International University FIU Digital Commons

$11-4-2013$

\title{
Synthesis of Carbon Nanotubes Using High Voltage and High Frequency Induction Field
}

Kalty Vazquez

kvasq003@fiu.edu

DOI: $10.25148 /$ etd.FI13120913

Follow this and additional works at: https://digitalcommons.fiu.edu/etd

Part of the Mechanics of Materials Commons

\section{Recommended Citation}

Vazquez, Kalty, "Synthesis of Carbon Nanotubes Using High Voltage and High Frequency Induction Field" (2013). FIU Electronic Theses and Dissertations. 1031.

https://digitalcommons.fiu.edu/etd/1031 


\section{FLORIDA INTERNATIONAL UNIVERSITY}

Miami, Florida

\section{SYNTHESIS OF CARBON NANOTUBES USING HIGH VOLTAGE AND HIGH FREQUENCY INDUCTION FIELD}

A thesis submitted in partial fulfillment of

the requirements for the degree of

MASTER OF SCIENCE

in

MECHANICAL ENGINEERING

by

Kalty Vazquez 
To: Dean Amir Mirmiran

College of Engineering and Computing

This thesis, written by Kalty Vazquez, and entitled Synthesis of Carbon Nanotubes Using High Voltage and High Frequency Induction Field, having been approved in respect to style and intellectual content, is referred to you for judgment.

We have read this thesis and recommend that it be approved.

Sakhrat Khizroev

Wenzhi Li

Arvind Agarwal, Co-Major Professor

Bilal El-Zahab, Co-Major Professor

Date of Defense: November 4, 2013

The thesis of Kalty Vazquez is approved.

$\begin{array}{r}\text { Dean Amir Mirmiran } \\ \text { College of Engineering and Computing } \\ \hline \begin{array}{r}\text { Dean Lakshmi N. Reddi } \\ \text { University Graduate School }\end{array}\end{array}$

Florida International University, 2013 


\section{ACKNOWLEDGMENTS}

I would like to express my appreciation to my advisor Dr. Arvind Agarwal, who has assisted and guided me through this important process. I am also extremely grateful to my committee members Dr. Bilal El-Zahab, Dr. Sakhrat Khizroev, and Dr. Wenzhi Li without whom this thesis would not be possible.

I would also like to extend my greatest appreciation to the faculty and staff at Florida International University Advanced Materials Engineering Research Institute (AMERI). This includes Neal Ricks, Dr. Yusuf Emirov, Walter Mckinley, Roozbeh Nikkhah Moshaie, and Mallika Sharan. Their assistance had been vital to the continuation of this research.

In addition, I would like to express my thanks to Francisco Alvarez and Javier Lopez who assisted in the construction and design of parts throughout this research.

Finally, I want to thank my family, whose unlimited support has helped drive me. 


\title{
ABSTRACT OF THE THESIS \\ SYNTHESIS OF CARBON NANOTUBES USING HIGH VOLTAGE AND HIGH- FREQUENCY INDUCTION FIELD
}

\author{
by \\ Kalty Vazquez \\ Florida International University, 2013 \\ Miami, Florida \\ Professor Arvind Agarwal, Co-Major Professor \\ Professor Bilal El-Zahab, Co-Major Professor
}

The fields of nanomaterial and nanostructures are some of the fastest growing fields in material science today. Carbon nanotubes are at the forefront of these fields and their unique mechanical and electrical properties are of great interest to those working in multiple engineering fields.

The overall objective of this study was to design and develop a new process and the equipment necessary, to synthesize carbon nanotubes using high voltage and a highfrequency induction field. This was the first time that a high voltage and an induction field have been used simultaneously in high yield production of carbon nanotubes.

The source of carbon came from acetylene with cobalt used as the doping agent. The carbon was molded into carbon nanotubes by the high-voltage field. The carbon nanotubes were characterized using electron microscope techniques. Raman spectroscopy was also used to reveal the defects and graphitic structures of the carbon nanotubes. 


\section{TABLE OF CONTENTS}

CHAPTER

PAGE

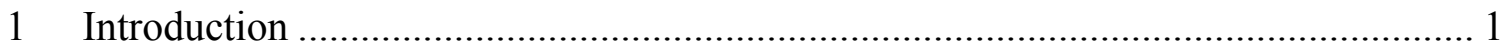

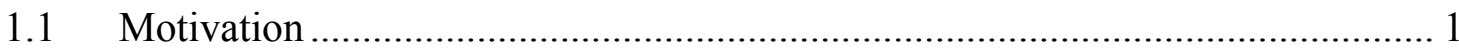

1.2 Design and Research Problems ........................................................................ 1

1.3 Objective of the Thesis.............................................................................. 2

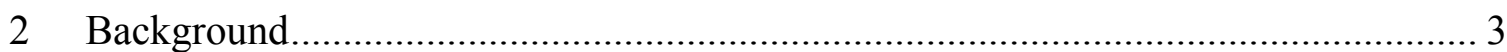

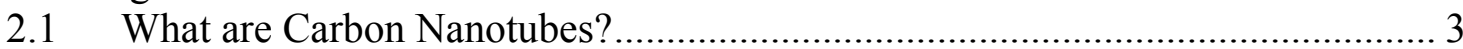

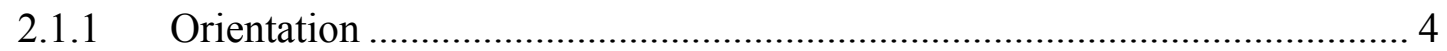

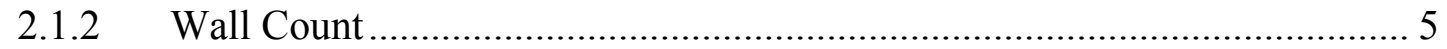

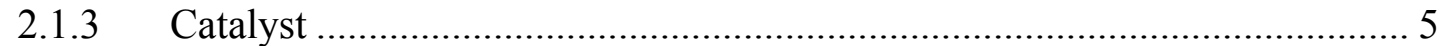

2.2 Common Carbon Nanotube Production Method..................................................... 6

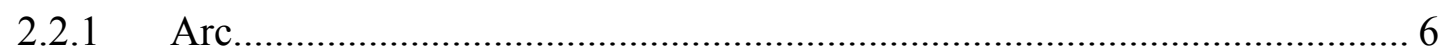

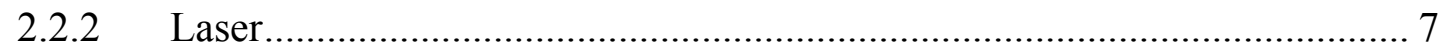

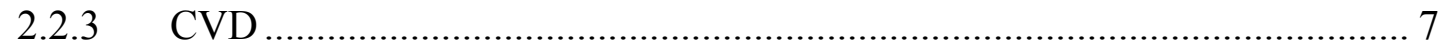

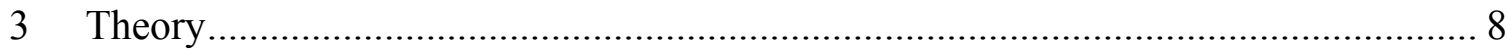

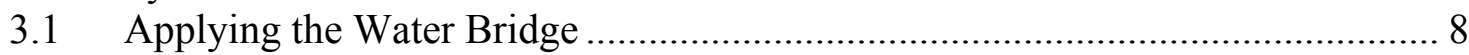

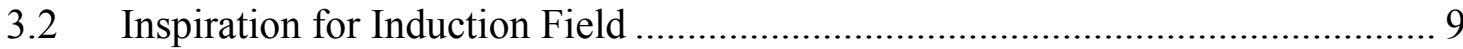

3.3 Machine Layout....................................................................................... 10

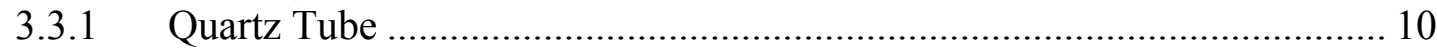

3.3.2 Reaction Chamber.......................................................................... 10

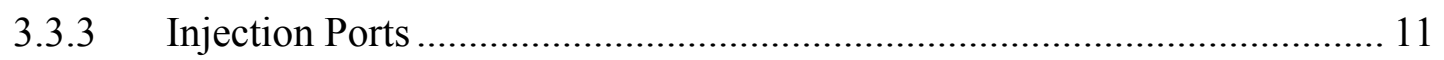

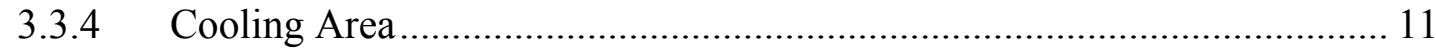

3.3.5 Theoretical Design ............................................................................... 12

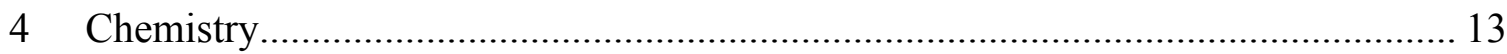

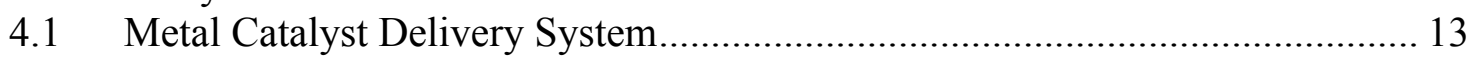

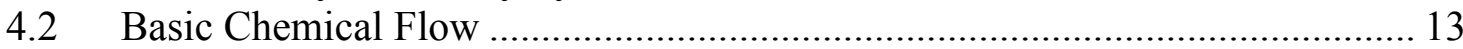

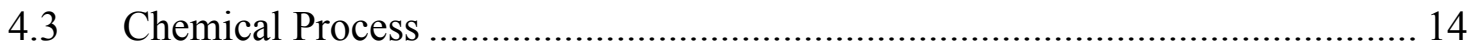

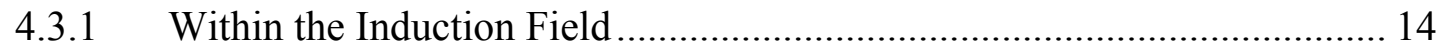

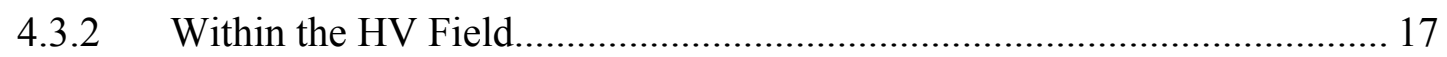

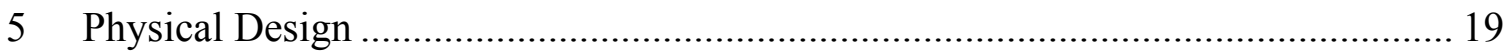

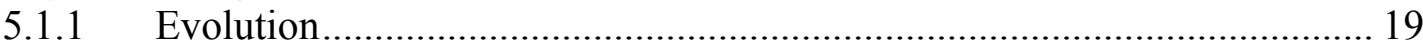

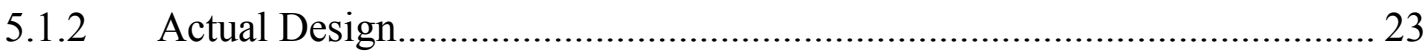

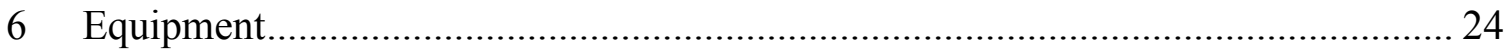

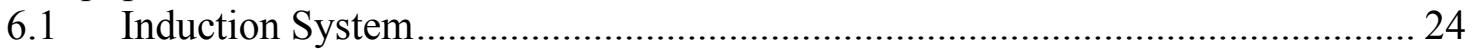

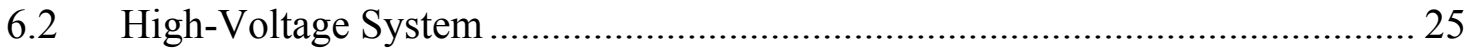

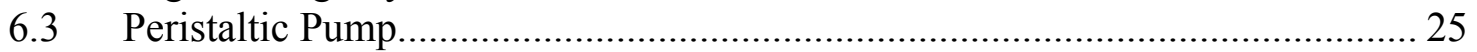

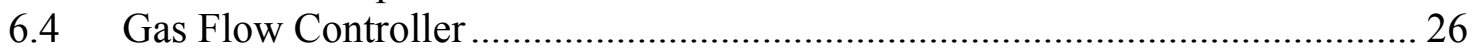




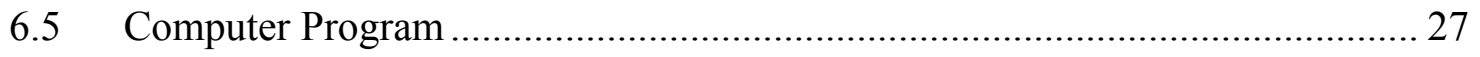

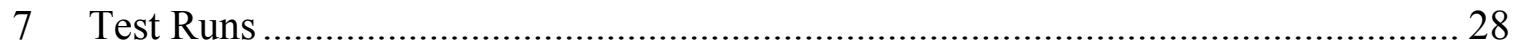

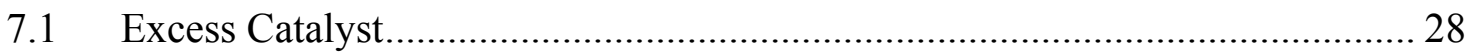

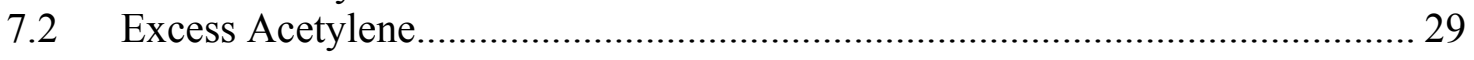

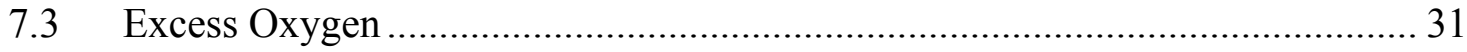

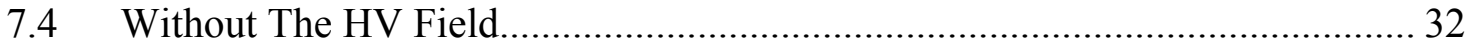

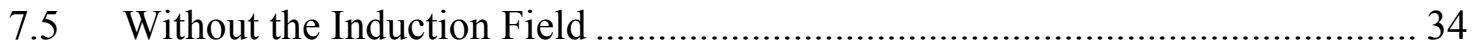

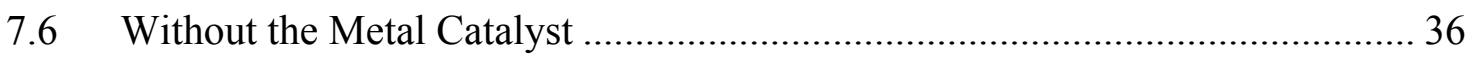

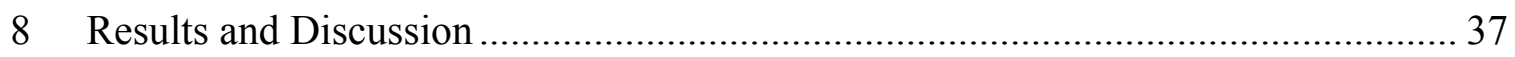

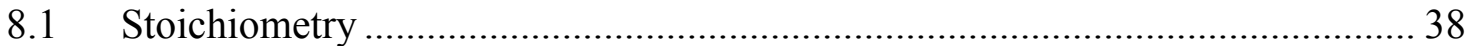

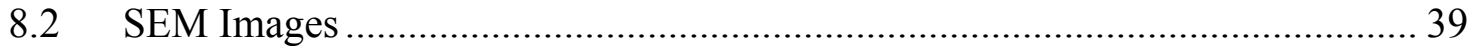

8.2.1 Energy - Dispersive X-ray Spectroscopy ............................................. 41

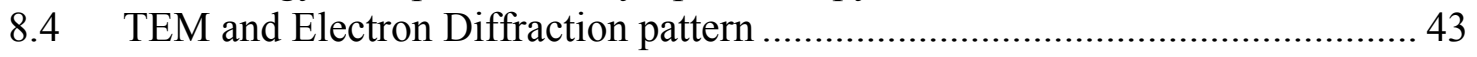

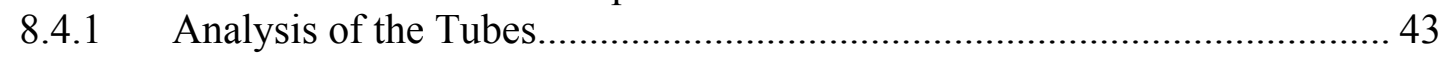

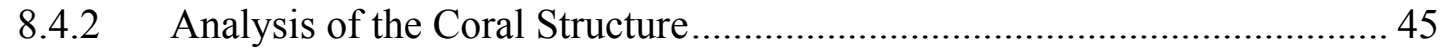

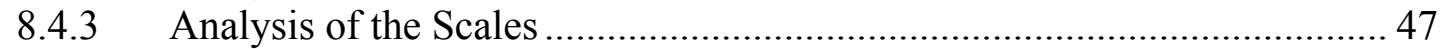

8.5 Raman Graphs ...................................................................................... 48

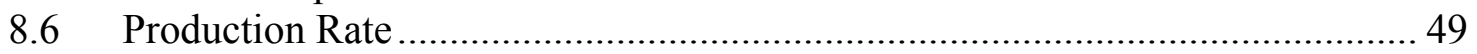

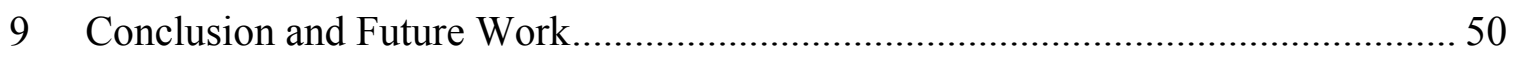

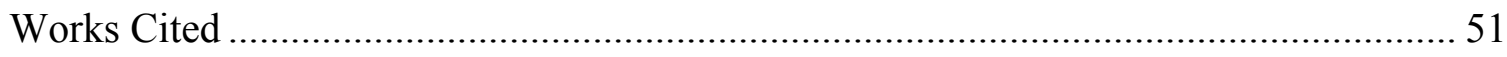

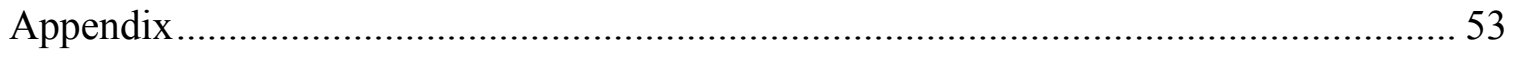




\section{TABLE OF FIGURES}

FIGURE

Figure 1 Graphite layers and carbon nanotube structure [1] .................................... 3

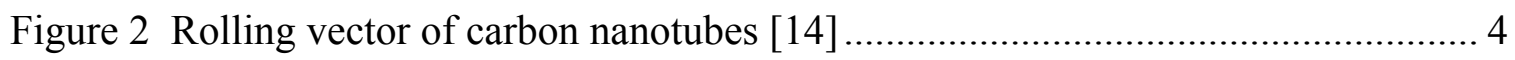

Figure 3 Single Walled vs. Multi Walled [19] ........................................................ 5

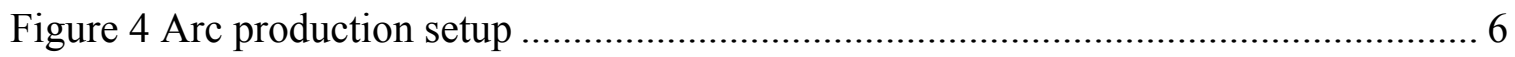

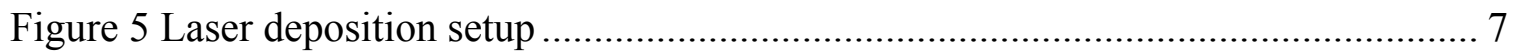

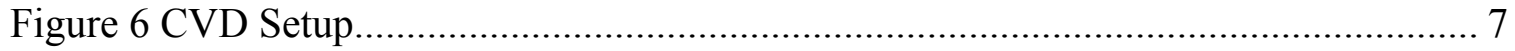

Figure 7 Water bridge photos (top) and infrared photos showing heat distribution through

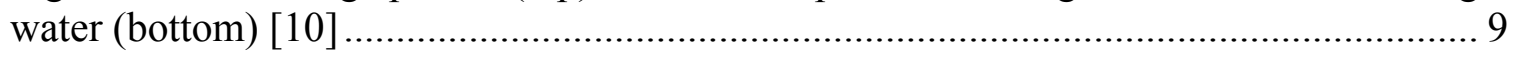

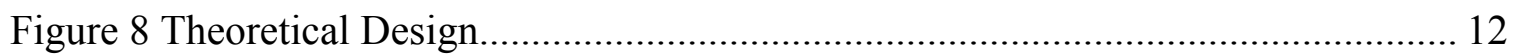

Figure 9 Temperature Distribution within the reaction chamber; red area represents $1100^{\circ}$

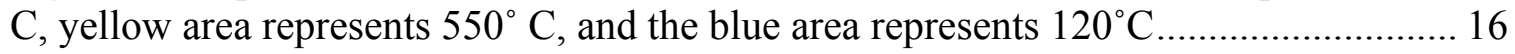

Figure 10 Atoms in the high-voltage field; gray balls represent carbon, blue represents

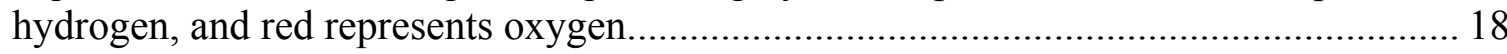

Figure 11 Evolutions of Injection Head; Images A,B, C, and D represent the first design that was used; Image E shows an attempt to increase mass drastically; Images F and G represents a complex design that used motors and mixing blades................................ 22

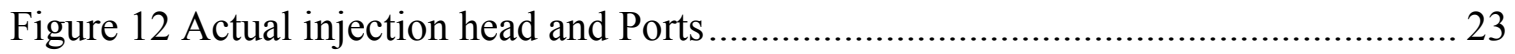

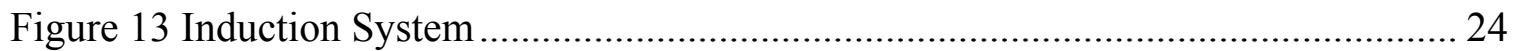

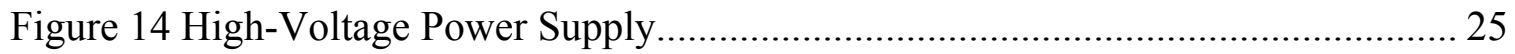

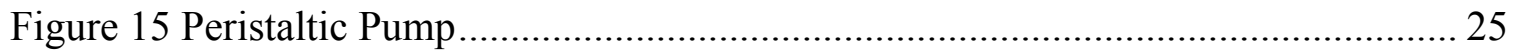

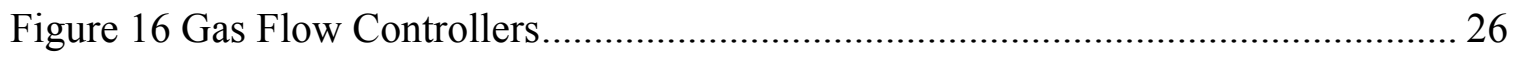

Figure 17 Computer Program; On the left side are the basic controls for the induction system, gas flow, and a few other parameters that were never installed; On the right there are two graphs that show the theoretical and actual flow of the gases for the last 60 seconds. 
Figure 18 Entire Setup; A - Computer Program; B - Induction System Head; C Induction System Power Source; D - Peristaltic Pump; E - High Voltage System; F Injection Head; G - Cooling Area

Figure 19 SEM of material produced without high voltage ....................................... 32

Figure 20 SEM of material produced without the induction field .................................. 34

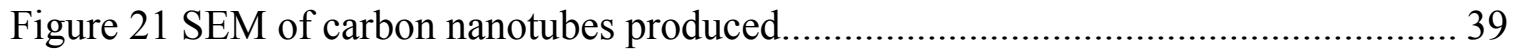

Figure 22 EDS of carbon nanotube sample produced ............................................ 41

Figure 23 SEM and TEM images of similar structures, highlighting the hollow structure

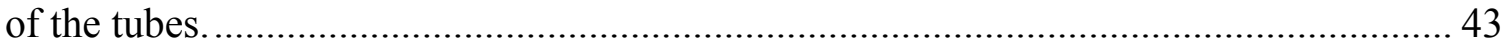

Figure 24 TEM Electron diffraction pattern for tube structures found in Figure 24 ....... 44

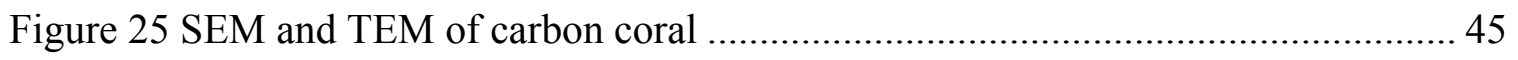

Figure 26 TEM electron diffraction pattern of coral structure found in Figure 24......... 45

Figure 27 Dr. Jianyang Wu simulation of carbon nanotube going through stress [11] ... 46

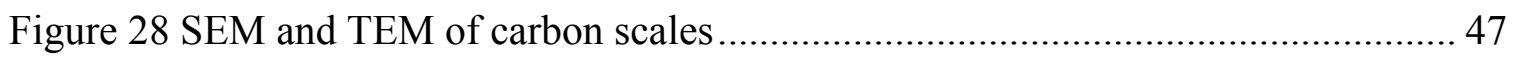

Figure 29 Electron diffraction pattern of carbon scale structure ................................ 47

Figure 30 Raman Comparision of Multi-Walled Carbon Nanotubes [4] ........................ 48 


\section{TABLE OF TABLES}

TABLE

PAGE

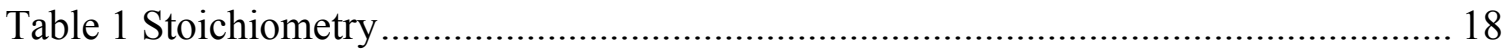

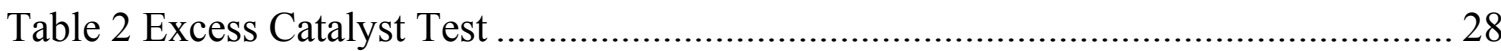

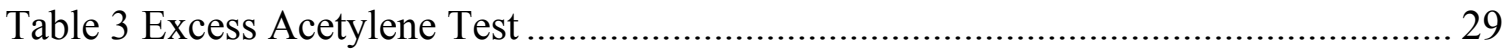

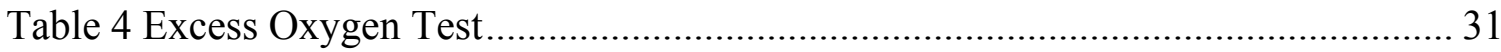

Table 5 No High Voltage Test ........................................................................................ 32

Table 6 No Induction Field Test .................................................................................... 34

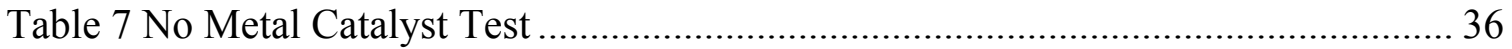

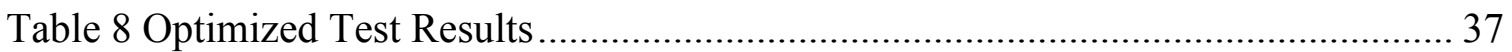

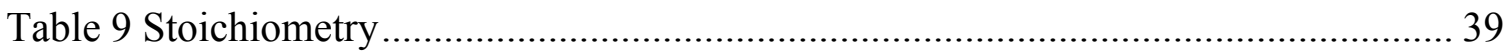

Table 10 Chemical composition of EDS sample shown in Figure 22 .............................. 41

Table 11 Results for Electron Diffraction Pattern ........................................................... 44

Table 12 Results for Electron Diffraction Pattern ........................................................... 46 


\section{Introduction}

\subsection{Motivation}

In the scientific community, a carbon nanotube is known as a material that has unlimited abilities. Introducing this material to the mass market (at a reasonable price) will cause a complete renovation of how engineers think about circuit design, material limitation, battery capacity, medical equipment, and numerous other products. Thousands of papers have been published on the ability of carbon nanotubes, depending on metal doping, to achieve countless tasks (such as electrical conductivity, tensile strength, electrical storage, etc.) many times better than what is currently being used.

The inspiration for this research was to bring carbon nanotubes to the mass market. The idea began as a theoretical conversation with my father about accelerating metal particles onto a metallic surface and concluded with the design seen below.

\subsection{Design and Research Problems}

The main issue encountered during this project was the multitude of variables. A total of 10 individual non-related variables were encountered: induction power output, voltage rating, grounding node distance, vacuum level, oxygen flow rate, acetylene flow rate, argon internal flow rate, argon external flow rate, catalyst solution flow rate, and catalyst solution composition. Having to fine tune these variables and find the right values was a long and careful process. 
The second issue that was encountered was related to the equipment. The induction system creates very strong magnetic fields making it impossible to have thermal couples or flow rate meters at or near the reaction chamber. All instruments that were less than 10 to 12 inches away from the reaction chamber would produce a high percentage of static in their readings and in many cases give random values. As an example, during initial testing, a thermal couple was placed inside the reaction chamber to measure the maximum temperature the induction system could reach. While the induction system was turned on, the thermal couple's reading would fluctuate from $-17^{0}$ $\mathrm{C}$ to $500^{\circ} \mathrm{C}$. Once the system was turned off the temperature would stabilize at $1100^{\circ} \mathrm{C}$.

The last issue was the power supply. The high-voltage system that was used could only limit the maximum voltage. With a system that could limit voltage as well as amperage, fewer issues would have been encountered during the research phase.

\subsection{Objective of the Thesis}

The objective of this thesis is to create a new carbon nanotube manufacturing method. The process will include an induction field and a high-voltage field. The material produced is verified by a scanning electron microscope (SEM) and the material's purity and structure is analyzed by a Raman spectrometer. 


\section{Background}

\subsection{What are Carbon Nanotubes?}

Carbon is considered the building block in our world. Pure carbon structures have unique properties; diamonds, for example, have a unique $3 \mathrm{D}$ structure that gives them high strength and high reflective properties.

Graphite is another unique structure, being one of the few known 2D structures; it is a very popular field of study for nanotechnology and nano-circuitry. When graphite is rolled into a tube shape, carbon nanotubes are created. This pure carbon material, like all other pure carbon materials, has very unique properties. Carbon nanotubes have three physical characteristics (orientation, wall count, and catalyst) that help determine its properties.
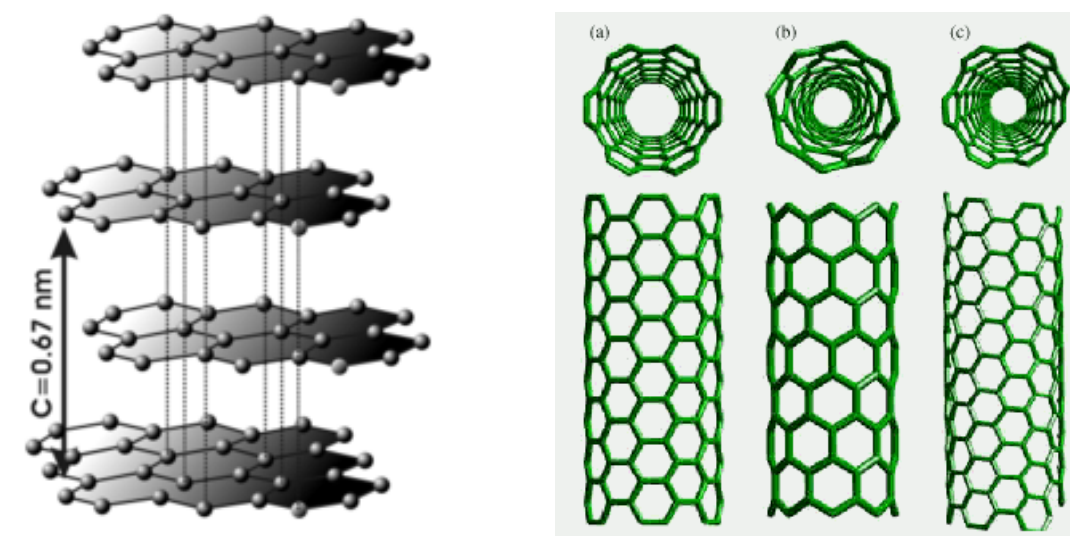

Figure 1 Graphite layers and carbon nanotube structure [1] 


\subsubsection{Orientation}

The orientation in which the graphite is rolled determines the structural properties of the material. Figure 2 shows a sheet of graphite; theta, $\theta$, denotes the angle of the roll with respect to the horizontal. The roll angle can also be denoted as a coordinate $(\mathrm{n}, \mathrm{m})$

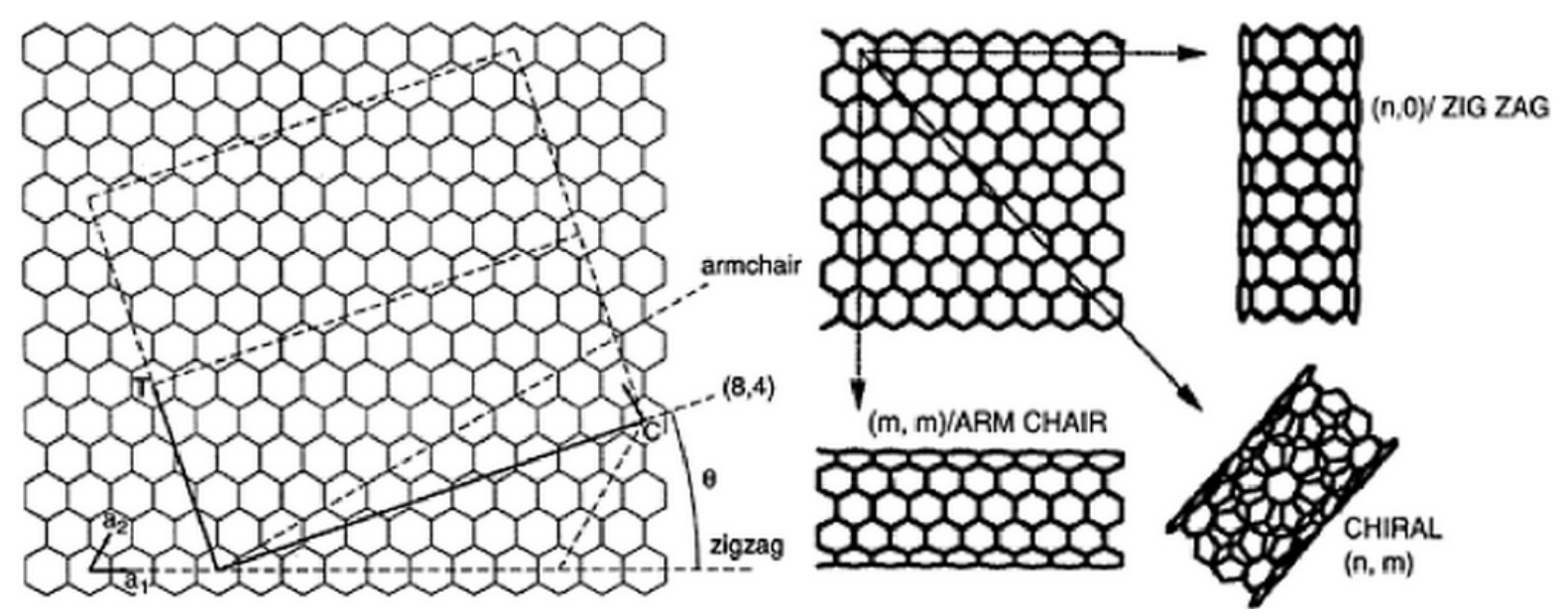

Figure 2 Rolling vector of carbon nanotubes [14]

by counting the number of carbon hexagons along the rolling vector. This vector becomes the exterior wall of the tube. Figure 2 also shows three examples of the most common orientations. 


\subsubsection{Wall Count}

During the production of carbon nanotubes, the number of walls is not limited to a single wall. The structure explained in the previous section is called a single-walled carbon nanotube (SWCNT), shown to the left in Figure 3. To the right in Figure 3 is the model of a multi-walled carbon nanotube (MWCNT). This structure is made when multiple layers of graphite are rolled onto a single tube. Each structure has its advantages and disadvantages when it comes to mechanical strength, electrical conductivity, and temperature resistance.
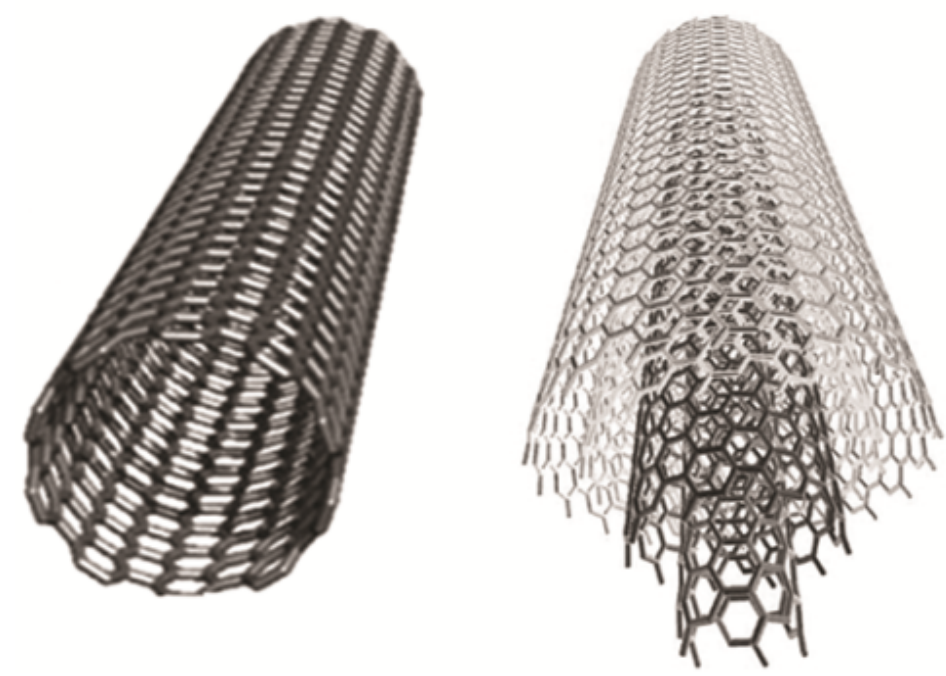

Figure 3 Single Walled vs. Multi Walled [19]

\subsubsection{Catalyst}

The creation of $100 \%$ pure carbon nanotubes is an extremely difficult feat; the use of metal catalyst, also known as doping agents, aids in the process [5]. The doping agent is a very small percentage of the total mass, normally less than $3 \%$, yet it has the most influence in controlling the physical properties. Depending on the doping agent, the carbon nanotubes could have a higher tensile strength than steel or become better conductors than gold. 


\subsection{Common Carbon Nanotube Production Method}

\subsubsection{Arc}

The arc method is the most common and simplest method to produce carbon nanotubes. This method uses two pure carbon rods placed end to end, separated by a small gap in an inert gas environment [6]. A low DC voltage with high current is placed at each end; the result is discharge vaporization, causing carbon to disperse from one graphite rod and deposit on the other as carbon nanotubes and other derivatives. The final product is extremely unorganized. The carbon nanotubes are of different lengths and wall counts and another type of carbon structure called fullerenes are also produced. Organizing and sorting the tubes and fullerenes is a long process.

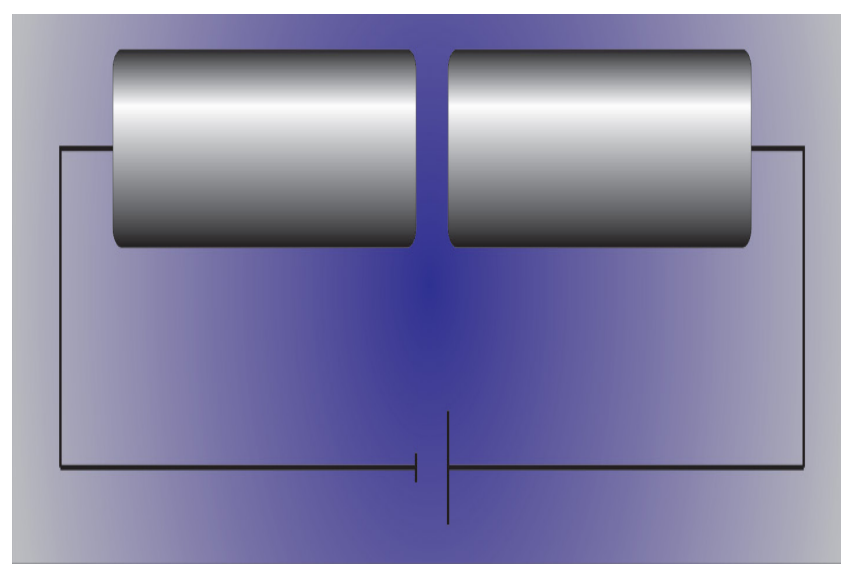

Figure 4 Arc production setup 


\subsubsection{Laser}

This method uses a high-purity graphite rod as a source of carbon and a metal substrate as the catalyst. Both are placed in an inert low-vacuum argon environment. A laser or a series of lasers are used to vaporize the graphite. This emits the carbon atoms into the chamber. The vaporized materials then start to settle at the bottom into carbon nanotubes in a "rope" or mat formation. This is a much more controlled production method; the time duration for one cycle is at least four hours.

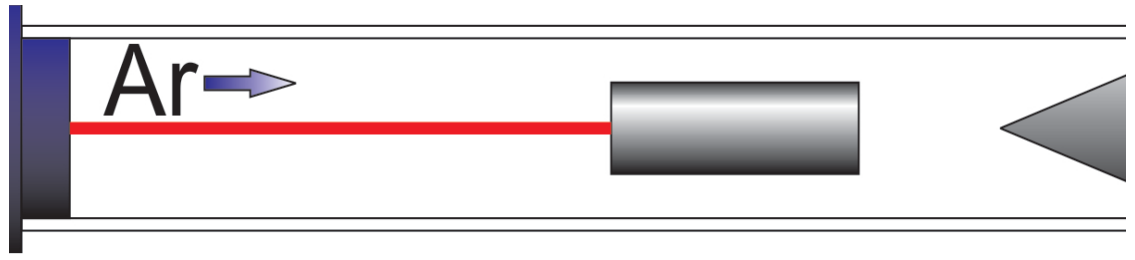

Figure 5 Laser deposition setup

\subsubsection{CVD}

The CVD method has a similar disposition as the laser method, yet the carbon and metal sources are from a chemical source [2]. The most common source of carbon is ethylene and the metal catalyst comes from a nickel- or cobalt-based product. This method runs much colder than the laser method, approximately $200^{\circ} \mathrm{C}$ colder, depending on the catalysts. The base materials are heated until they pass through a pyrolytic process. The free particles are injected into a cooling chamber where they settle on the metal substrates.
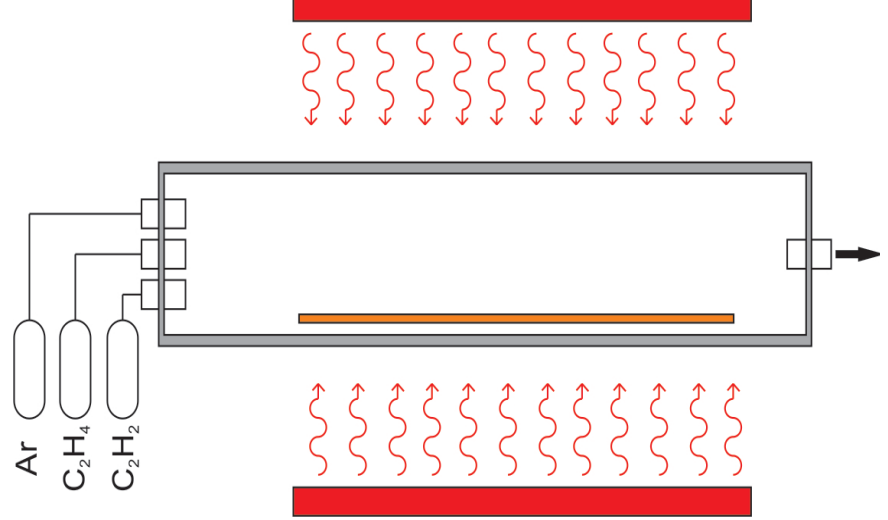

Figure 6 CVD Setup 


\section{Theory}

\subsection{Applying the Water Bridge}

The main theory in this thesis is how the movement of electrons can cause carbon atoms to settle in a predetermined formation. The water bridge was originally discovered in 1894 by Sir William George Armstrong. It was not until recent years (2005 to 2008) that the phenomenon was dissected, exposing the electrical properties, mechanical properties, heat transfer phenomenon, and mass transference.

It is common knowledge that water can carry a flow of electrons. What was not expected is that the movement of the electrons is strong enough to counteract gravity across a $10 \mathrm{~mm}$ gap. The water bridge experiment was reproduced by Jakob Woisetschlager, Karl Gatterer, and Elmar C. Fuchs in 2009 using $25 \mathrm{kV}$ at $.5 \mathrm{~mA}$. During their experiment, they moved 40 milligrams of water a second from the Anode beaker to the Cathode beaker [7, 8, 10]. 
These findings add validity to the first part of the theory: it is possible to create a bridge using carbon atoms as the conductor. The next point is that the carbon atoms will move and create the structures of my choosing (this will be explained in detail later).
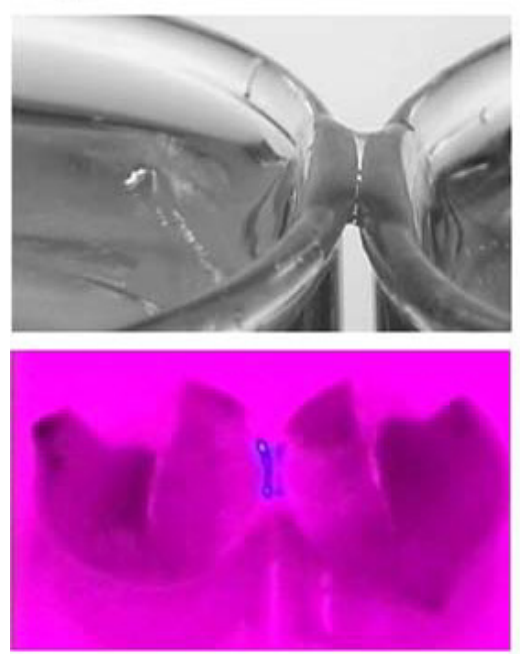

$15 \mathrm{~s}$
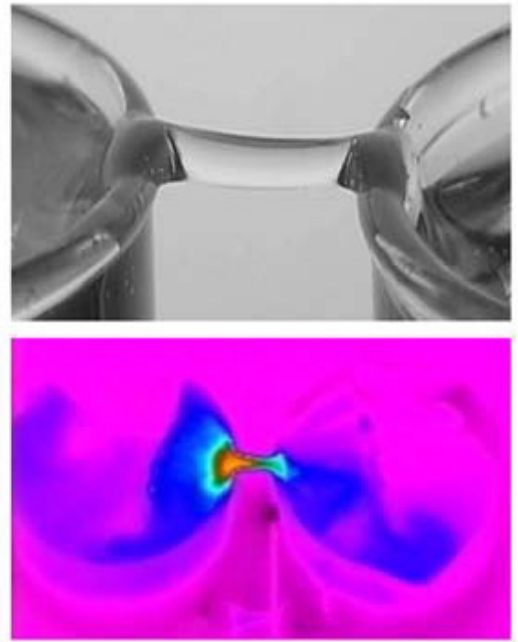

$110 \mathrm{~s}$
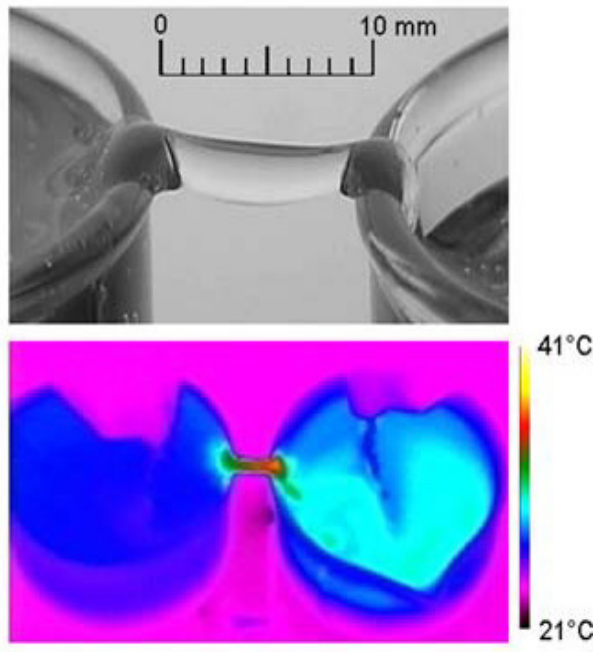

$352 \mathrm{~s}$

Figure 7 Water bridge photos (top) and infrared photos showing heat distribution through water (bottom) [10]

\subsection{Inspiration for Induction Field}

Induction field generators are more commonly seen on the production lines of metallic products as a source of heat. It has become more common practice in small labs to use small induction systems with a metal-lined ceramic crucible as a heat source.

While in the initial design stages of the reaction chamber, cartridge-style heating elements were going to be used because of their simplicity and ease of control would simplify the heating of the reaction chamber. After reading a paper from the National Key Laboratory of Nano/Micro Fabrication [16], however, the concept of the induction system was chosen instead. The team from this lab used an active carbon fiber (ACF) crucible with an inductive heating cylinder. They used the heat produced by the induction 
system to convert $\mathrm{SiO}$ power to $\mathrm{SiC}$ nanowire. They credit the high temperature and magnetic fields for the production of the $\mathrm{SiC}$ tubes.

\subsection{Machine Layout}

The design aspect of this research was incredibly intricate with the introduction of a high-voltage field and an induction field causing large concern for user safety and cost. In addition, induction fields cause most off-the-shelf sensors to malfunction unless they are correctly isolated from the high-intensity magnetic fields and the high voltage.

\subsubsection{Quartz Tube}

The quartz tube contains the reaction environment and allows the induction field to pass through it with minimal to little resistance or reactance, creating an insulating barrier for heat and electricity. Its transparency allows us to observe the reaction and the creation of the carbon nanotube at the exit of the reaction chamber. Quartz's high temperate resistance makes it perfect for this application; since it is able to withstand over $1500^{\circ} \mathrm{C}$, it will not melt when the reaction chamber is heated.

\subsubsection{Reaction Chamber}

The reaction chamber is a half-inch inner-diameter ceramic tube with a thick steel

jacket. The steel jacket is exposed to an induction field that, along with the ceramic tube, reaches a temperature of $1200^{\circ} \mathrm{C}$. The chemicals are injected within this area. 


\subsubsection{Injection Ports}

The injection ports are six white connectors that inject the gasses and liquids into the reaction chamber. The ports are connected to long stainless steel tubes that guide the chemicals. Stainless steel is used for two reasons: 1), it retains a high tensile strength while being heated, allowing the reaction chamber to be heavier; and 2), stainless steel is not affected by the induction field, permitting the top plate to remain at a lower temperature. This is vital for continuous operation of the machine. If the head starts to heat up, it is possible that the chemicals start to evaporate or start the pyrolytic process before intended.

Four of the injection ports introduce the chemicals at the top inside the reaction chamber; these are used to inject the carbonated gasses, catalyst, and noble gas.

One of the injection ports is capped at the end and has a small cut, forcing the injected gas around the outside of the reaction chamber. This helps create an inert environment and pushes the carbon nanotube towards the bottom.

The final injection port, located in the middle of the reaction chamber, is the oxygen injection port. This stainless steel tube is much longer and injects the oxygen right before the exit of the reaction chamber. It is also used as our anode, which is explained later.

\subsubsection{Cooling Area}

The cooling area is the long stretch of quartz tube that allows the material to settle, fall, and cool. This area is essential to allow the reaction to finish. 


\subsubsection{Theoretical Design}
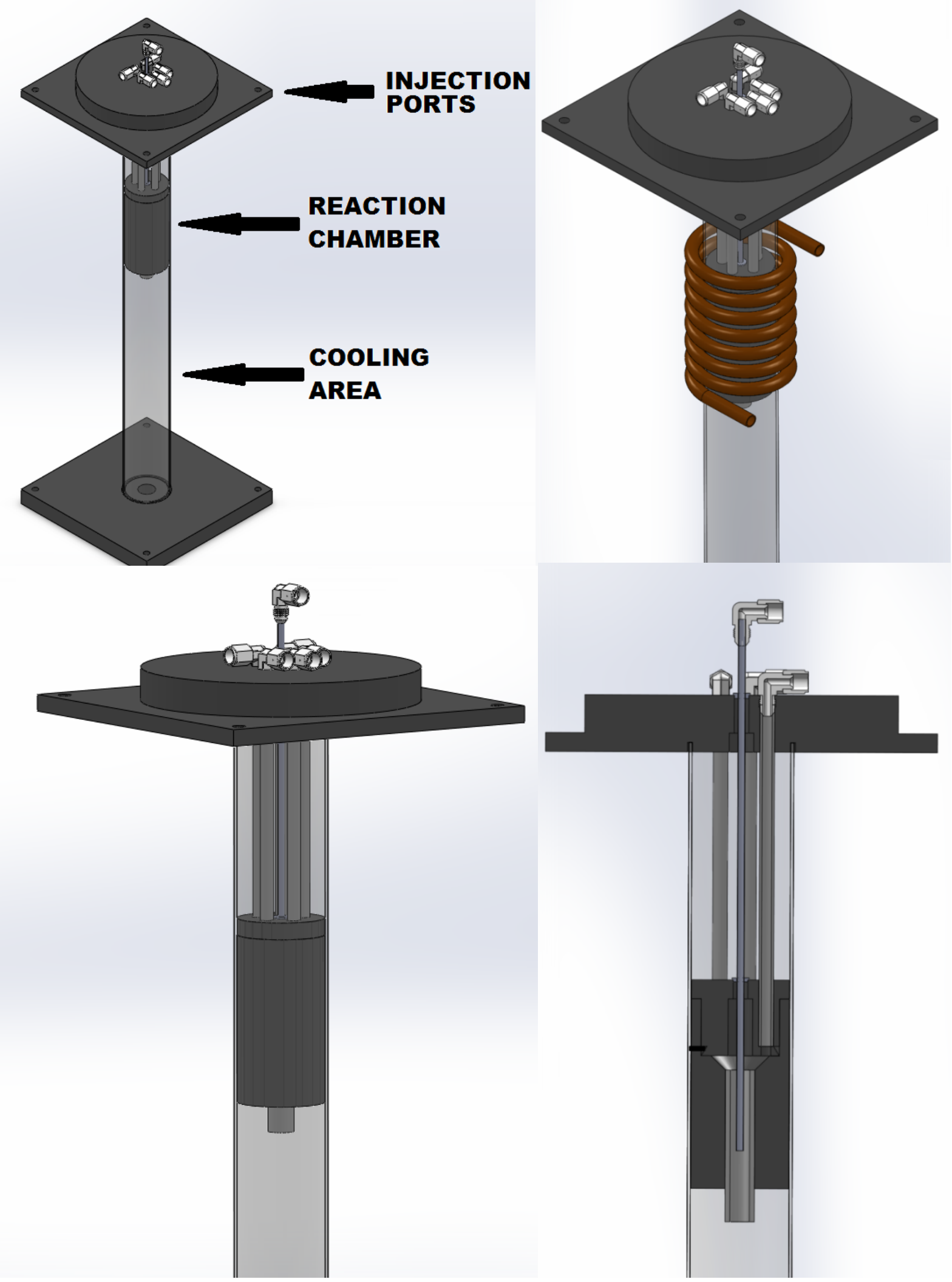

Figure 8 Theoretical Design 


\section{Chemistry}

\subsection{Metal Catalyst Delivery System}

Carbon nanotubes' unique abilities and properties can be drastically modified depending on the catalysts they are doped with. The method of injecting a metal catalyst, therefore, is a critical component to the process. During these experiments, a new method of delivering doping agents was devised. In this method, metallic salts are diluted in a solution of water and methanol, named the methanol catalyst solution, and then injected as a liquid into the reaction chamber. This is done by first mixing the metallic salts, cobalt nitrate $\mathrm{Co}\left(\mathrm{NO}_{3}\right)_{2}$, with water to create a highly concentrated solution, which is then diluted in methanol. A diluted methanol solution is used instead of a diluted water solution because methanol, $\mathrm{C}_{2} \mathrm{H}_{3} \mathrm{OH}$, decomposes extremely easily. In addition, the carbon within the methanol contributes to the production of carbon nanotubes.

The challenge at this stage of the project was the minimum injection speed on our current peristaltic pump of $0.3 \mathrm{ml} / \mathrm{min}$, which is still very high. One way of controlling the amount of cobalt that is injected is by diluting a higher or lower percent of cobalt nitrate/water solution into the methanol. Our final metal catalyst injection solution is $\left.\mathrm{Co}\left(\mathrm{NO}_{3}\right)_{2}+\mathrm{H}_{2} \mathrm{O}\right)+\mathrm{CH}_{3} \mathrm{OH}$.

\subsection{Basic Chemical Flow}

As previously explained, there are six injection ports. The first four injection ports are used for the carbonated gasses, metal catalysts, and a noble gas. Our carbonated gas is acetylene, which was chosen due to its high percentage of carbon: it contains $85 \%$ carbon 
and $15 \%$ hydrogen by mass. In addition, the required temperature to initiate a pyrolytic process is relatively low when compared to other carbonated gasses. A small amount of argon is also injected inside the reaction chamber to help avoid congestion by the production of carbon nanotubes and to increase the conductivity of the gasses within the reaction chamber. Figure 9-A shows the flow of the gasses and liquids from the injection ports into the reaction chamber: Red represents acetylene, green the methanol catalyst solution, blue argon, and yellow oxygen.

The center injection port deposits the oxygen near the end of the reaction chamber, which is used to react with the hydrogen and create water.

The final injection port adds argon around the outside of the reaction chamber. Argon is used to create a stable environment, help cool off the carbon nanotubes during the cooling section, and assist in pushing the carbon nanotubes towards the bottom of the reaction chamber.

\subsection{Chemical Process}

\subsubsection{Within the Induction Field}

The acetylene, $\mathrm{C}_{2} \mathrm{H}_{2}$, and methanol catalyst solution, $\left.\mathrm{Co}\left(\mathrm{NO}_{3}\right)_{2}+\mathrm{H}_{2} \mathrm{O}\right)+\mathrm{CH}_{3} \mathrm{OH}$, are injected into the top of the reaction chamber. As they flow down through the reaction chamber, they pass through the induction field where the steel jacket and ceramic tube reach temperatures of $1100^{\circ} \mathrm{C}$. At this temperate, both of the injected materials go through a pyrolytic process that weakens the bonds between the atoms and separates each compound into individual atoms. At this moment, the freed carbon, nitrogen, oxygen, and 
cobalt atoms start to flow down towards the end of the heated chamber where the central injection tube ends. This tube is the anode of the high voltage source and introduces oxygen.

Figure 9-B shows the temperature distribution within the reaction chamber. The red area in Figure 9-B represents $1100^{\circ} \mathrm{C}$, yellow represents $550^{\circ} \mathrm{C}$, and the blue area represents $120^{\circ} \mathrm{C}$. 

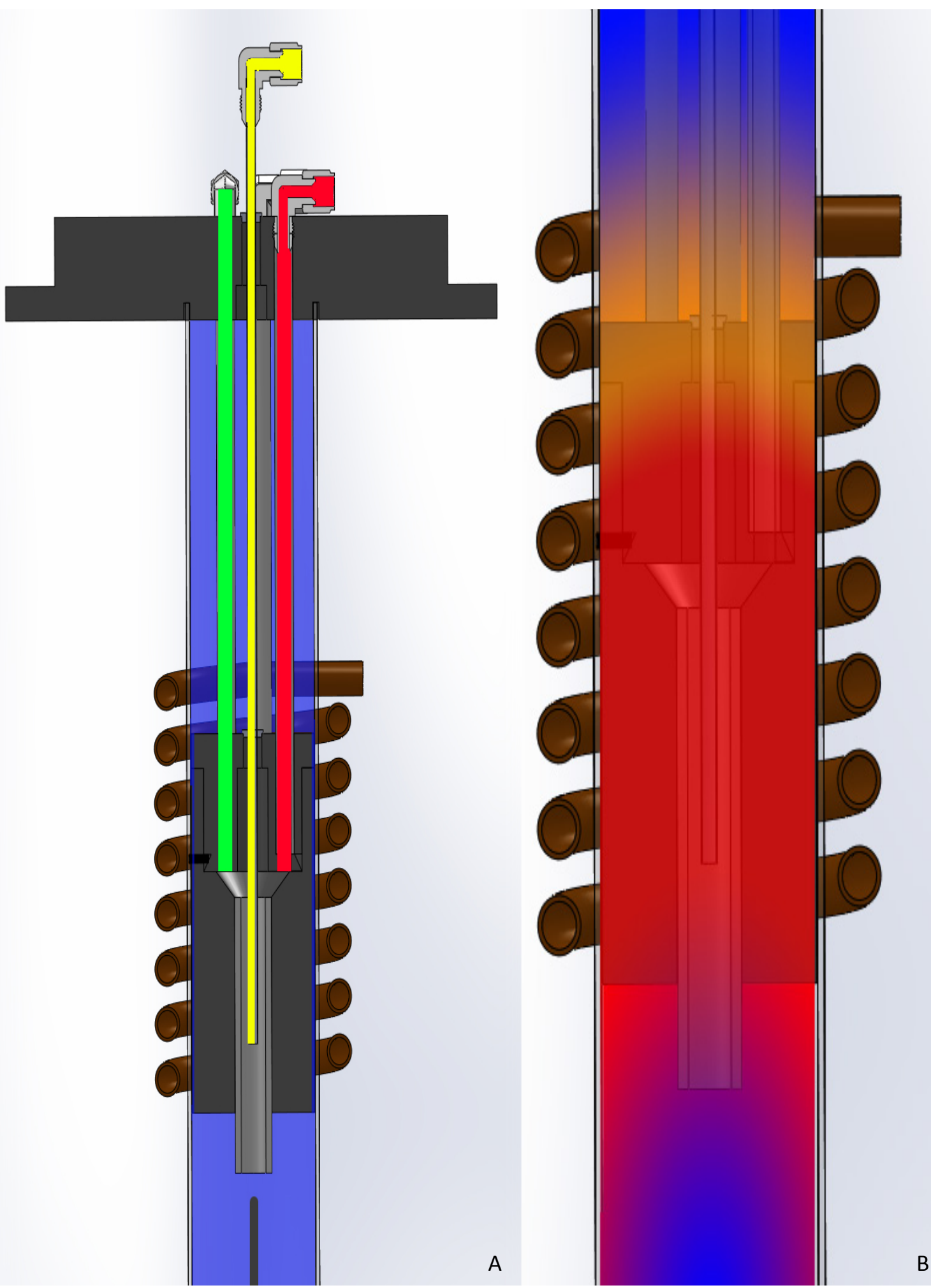

Figure 9 Temperature Distribution within the reaction chamber; red area represents $1100^{\circ} \mathrm{C}$, yellow area represents $550^{\circ} \mathrm{C}$, and the blue area represents $120^{\circ} \mathrm{C}$ 


\subsubsection{Within the HV Field}

As the induction field ends, the individual carbon, nitrogen, oxygen, and cobalt atoms move into the high-voltage field and the atoms start to cool down, reversing the pyrolytic process. Within the high-voltage field there is a constant movement of electrons from our anode, the oxygen injection tube, to our cathode, a grounding rod. As the electrons flow, a small percentage of them are consumed by bonding the oxygen and hydrogen into water, $\mathrm{H}_{2} \mathrm{O}$. The nitrogen and argon flow through the field unchanged. The carbon atoms start to bond to other carbon atoms and cobalt atoms.

The final carbon structure must be a conductive structure, as to not impede the movement of the electrons that are using it as a bridge. The carbon structure with the highest conductivity is a carbon nanotube. Once the initial carbon nanotube structure is made, more carbon atoms will settle at either end. As the carbon nanotube leaves the high-voltage field and enters the cooling area, it loses all charge and falls, with the assistance of the argon, towards the collection area.

In the event that the carbon settles into any other form, a diamond, for example, the form will have a large resistive $(\Omega)$ value. As Ohms Law states, a large resistive value with a high voltage will cause increased current to pass through that structure. This increased current will result in an increased temperature that will eventually lead to the decomposition of the structure, effectively restarting the pyrolytic process for those affected atoms.

Figure 10 shows the process: red represents oxygen, blue represents hydrogen, gray represents carbon, and the purple circle represents the inert nitrogen and argon. Cobalt is in such a low percent that it is not shown. 


\begin{tabular}{lll}
\hline Input & & Output \\
\hline Methanol Catalyst Solution & $\left(\mathrm{Co}\left(\mathrm{NO}_{3}\right)_{2}+\mathrm{H}_{2} \mathrm{O}\right)+\mathrm{CH}_{3} \mathrm{OH}$ & $\mathrm{Co}+\mathrm{C}$ \\
\hline Acetylene & $\mathrm{C}_{2} \mathrm{H}_{2}$ & $\rightarrow \mathrm{H}_{2} \mathrm{O}$ \\
\hline Oxygen & $\mathrm{O}_{2}$ & $\rightarrow \mathrm{N}_{2}$ \\
\hline Argon & $\mathrm{Ar}$ & $\mathrm{Ar}$ \\
\hline
\end{tabular}

Table 1 Stoichiometry

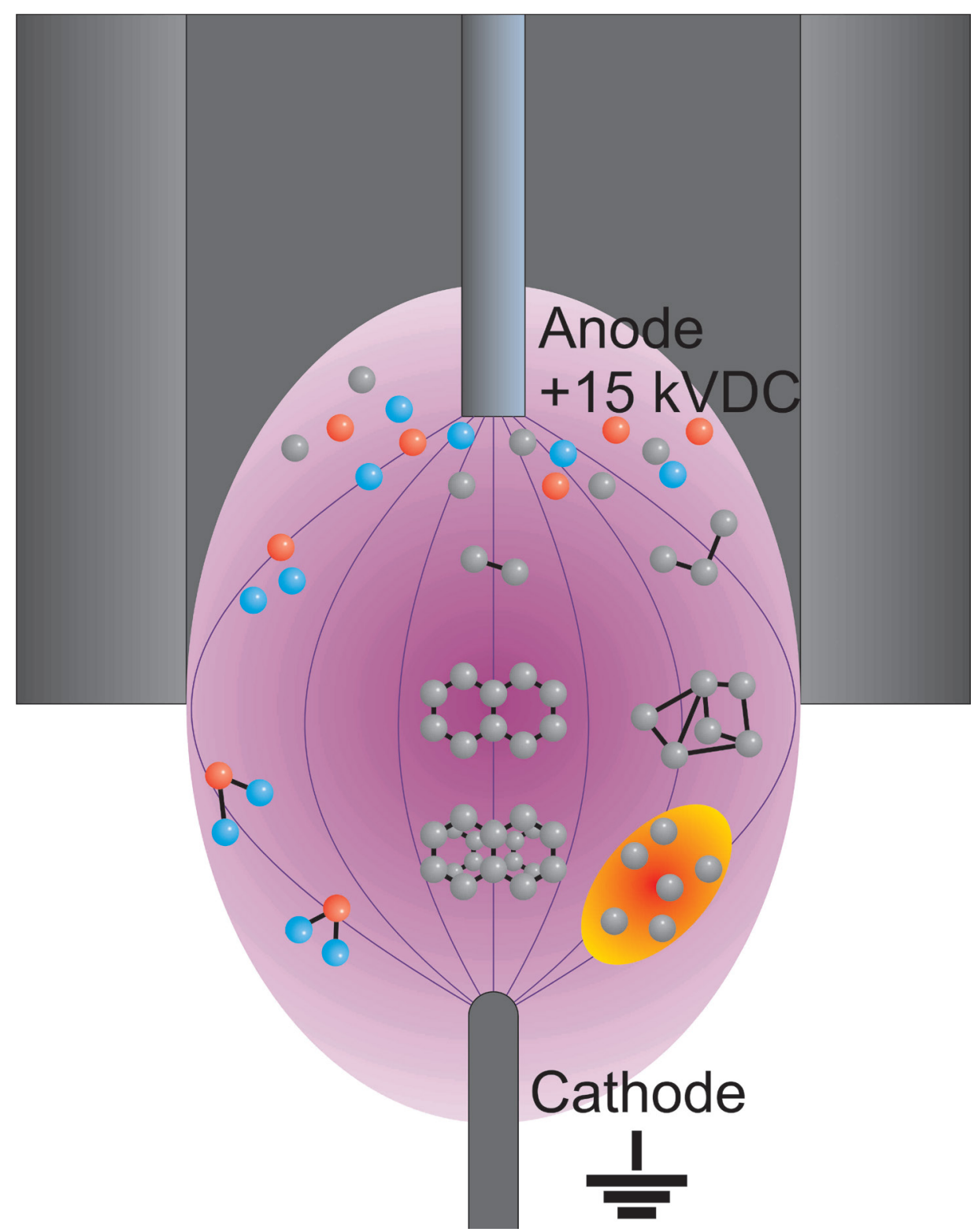

Figure 10 Atoms in the high-voltage field; gray balls represent carbon, blue represents hydrogen, and red represents oxygen 


\section{Physical Design}

\subsubsection{Evolution}

The injection machine's design has evolved drastically; however, the key points in the design have stayed the same. The reaction chamber has always been heated with an induction system. The use of high voltage in the injection heat means that conventional heating elements cannot be used because of the risk of the high voltage passing through the thermal couple and into the controllers or main power grid, thus limiting our heating to a radial heat. By avoiding contact, any risk to the user would be eliminated. Other radial heat systems cannot reach the high temperatures required, leaving an induction system as one of the few choices left.

The injection head has always had the same role, which was to inject the chemicals safely into the reaction chamber and mix them while being able to transmit the high voltage to the heated section of the chamber. The design of the injection head, however, has gone through several iterations.

The original design, shown in Figure A through Figure D, used three aluminum plates for the head. The top plate was designed to hold the ceramic tubes using Teflon rings and steel bolts; the middle plate was designed to hold the steel "reaction core" in place and guide the chemicals into the reaction chamber; the bottom plate was used to hold the quartz tube. This design failed for two reasons. First, the reaction core was a 3/8inch steel round bar. While it was able to reach the required temperature of $1100^{\circ} \mathrm{C}$, it was not able to maintain this temperature. The core's temperature would begin to decrease rapidly as the acetylene and alcohol went through the pyrolytic process. The 
reaction core did not have enough of a mass to use the induction field efficiently, thus this design cooled down too quickly. The second flaw was the ground wire design. The ground wire was wrapped in a ceramic tube that was held by the top plate. This would occasionally cause a short circuit through the ceramic which would in turn cause the high-voltage power supply to turn off.

The next version of the design, as seen in Figure 11-E, was a large steel tube with a catch. The catch is the section toward the bottom of the reaction chamber that flares upwards. This area would be used to collect the catalyst solution and assure it went through the pyrolysis process completely. The objective was to use a larger mass, giving us a higher temperature and a large thermal inertia. The objective of the catch was to create turbulence within the reaction chamber and cause heat to transfer more uniformly. Unfortunately, having such a large mass meant that the exit of the reaction chamber had to be very large, making it difficult to guide the electrons through the cloud of gasses evenly. While some carbon nanotubes were created, the percentages were very low.

The third version of the injection head, as seen in Figure 11- F and Figure 11-G, was an attempt at adding a motor meant to assist in mixing the chemicals. The motor was connected to a propeller that would help mix the atoms and force them downwards after the pyrolytic process had occurred. The complexity of this design and the large opening caused it to be unsuccessful. When testing this injection head, the high voltage caused the mixing motor to stop working or resulted in the burn out of the motor's controller. The ground in this design is the small conic piece under the mixing blade and its objective was to create a smaller area where there could be a constant movement of electrons. The 
spacing was too small and carbon nanotubes would get stuck between the two plates, shorting out the high-voltage power supply.

While the design has changed, the process has remained the same: inject the chemicals in a controlled manner, heat them until pyrolysis is reached and oxygen bonds with hydrogen while carbon bonds with catalysts inside of an electric field. 


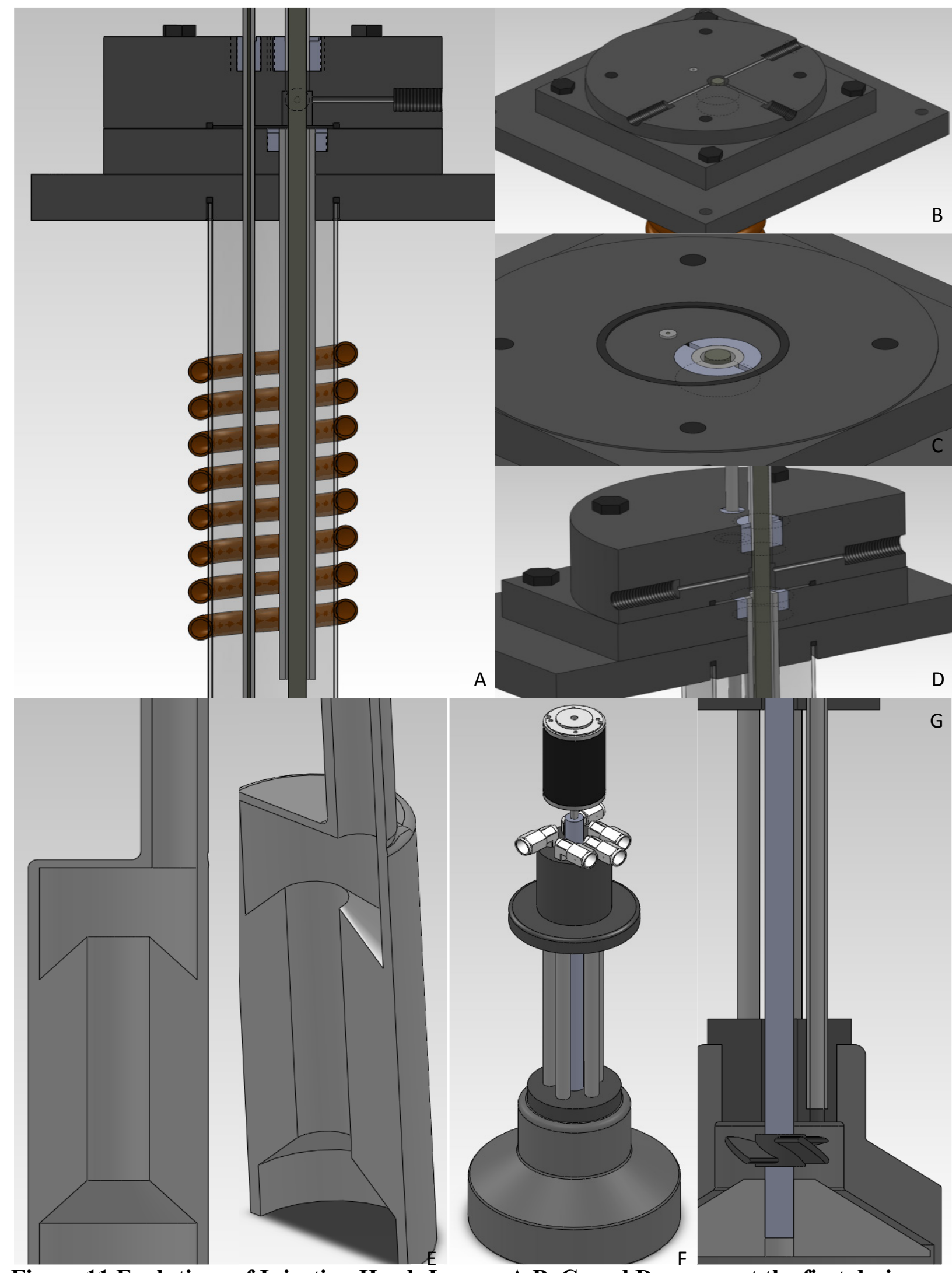

Figure 11 Evolutions of Injection Head; Images A,B, C, and D represent the first design that was used; Image $E$ shows an attempt to increase mass drastically; Images $F$ and $G$ represents a complex design that used motors and mixing blades 


\subsubsection{Actual Design}

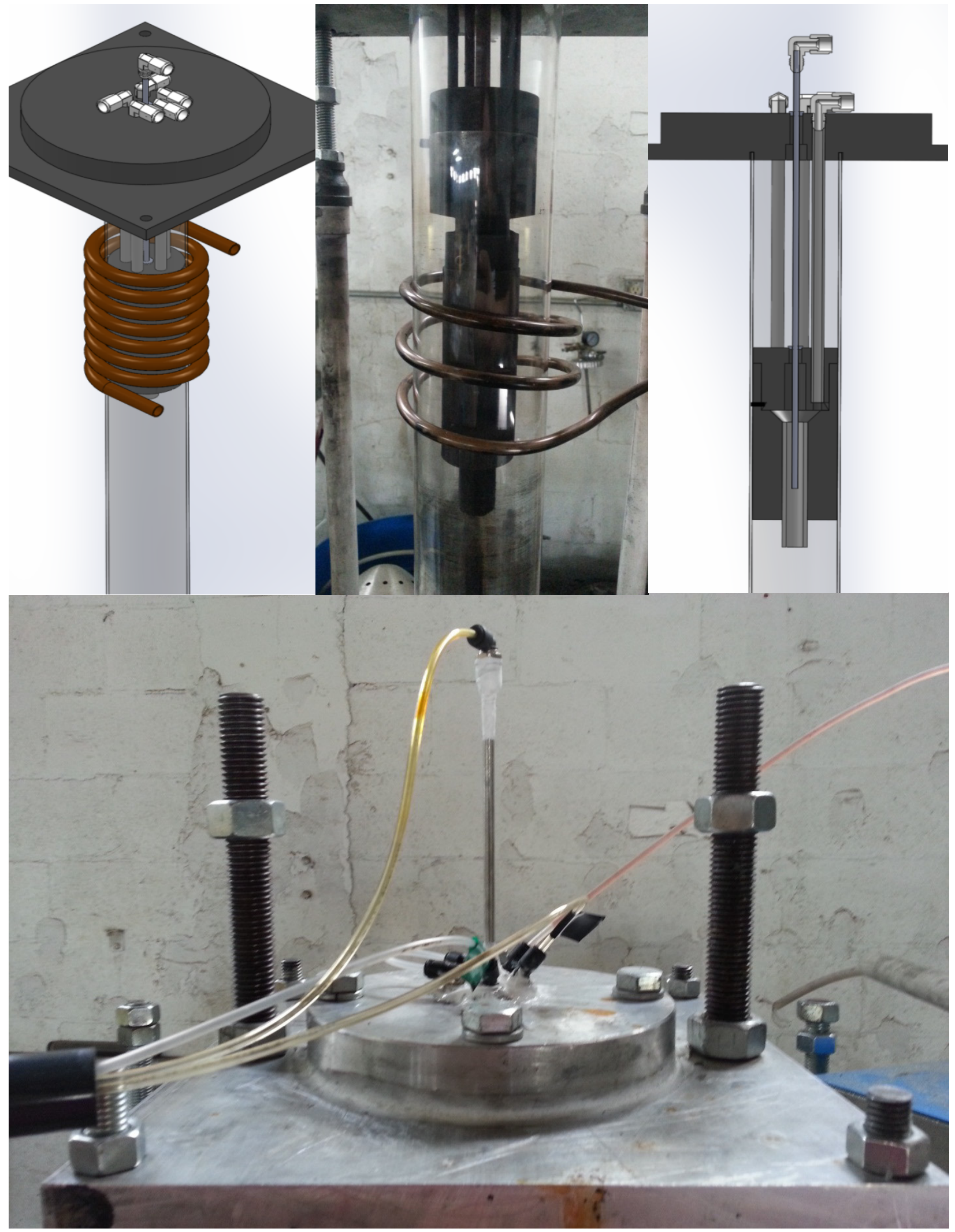

Figure 12 Actual injection head and Ports 


\section{Equipment}

\subsection{Induction System}

The induction system is the heat source for the reaction chamber. Induction systems produce a high-amperage high-frequency output, ranging from $50 \mathrm{kHz}$ to 350 $\mathrm{kHz}$ depending on the metal within the field. The high-frequency output that is produced is transmitted to a hollow copper coil. The coil is wrapped around the Reaction Chamber outside of the quartz tube, represented in Figure 13. Any metal object that is within the high-frequency field will reach temperatures of $1100^{\circ} \mathrm{C}$; this includes the copper coil that is producing the field. Cool water is pumped through the copper coil to control its temperature.

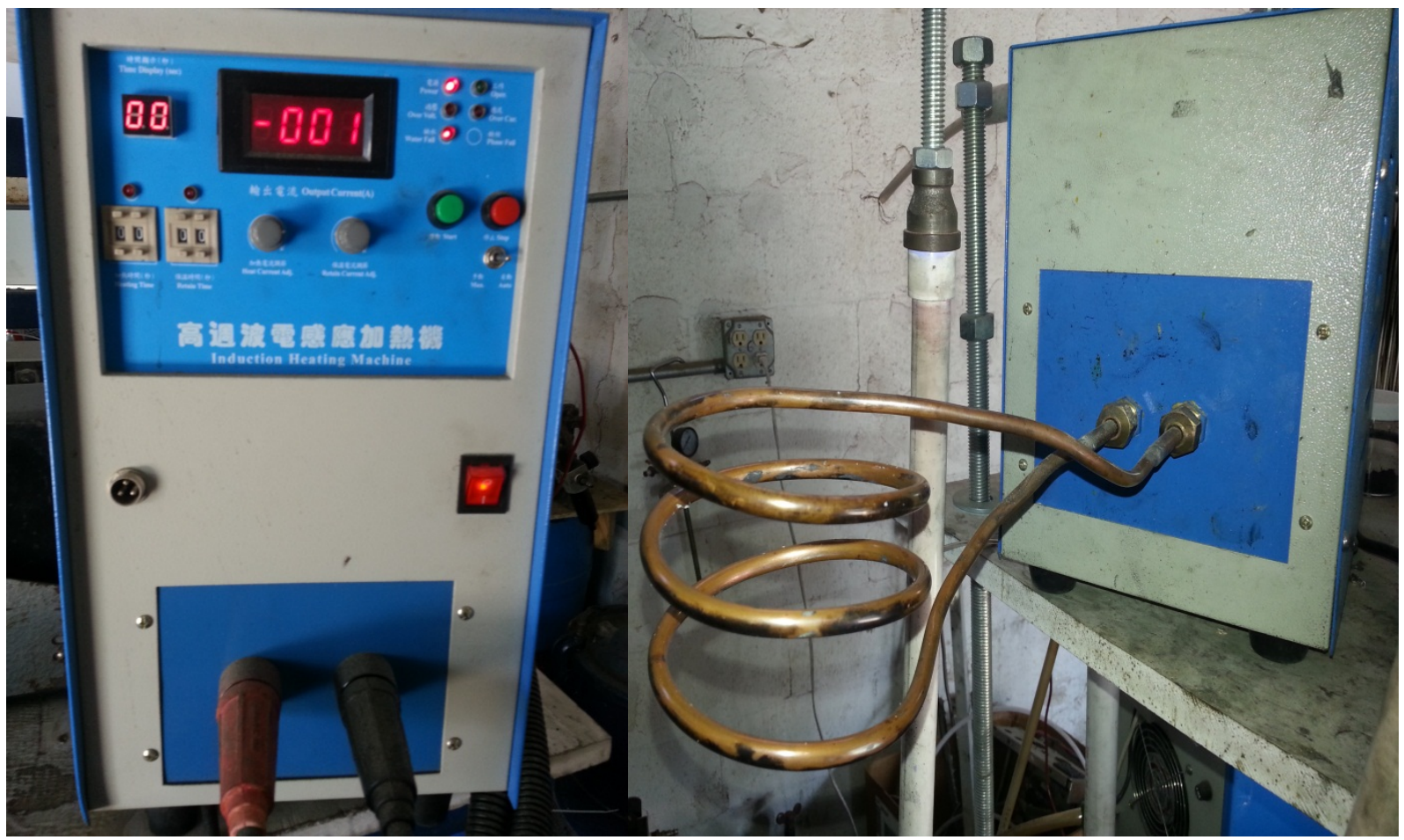

Figure 13 Induction System 


\subsection{High-Voltage System}

The high-voltage system is what provides us with the high potential difference that will shape the carbon nanotubes. The power supply used can produce a voltage of 30 $\mathrm{kV}$ at $20 \mathrm{~mA}$.

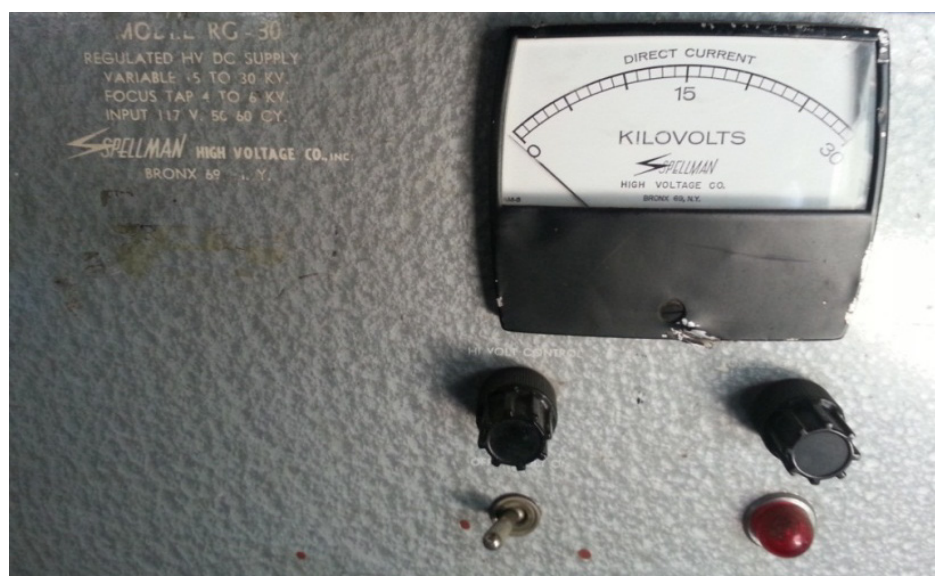

Figure 14 High-Voltage Power Supply

\subsection{Peristaltic Pump}

The peristaltic pump was supplied by Omega Engineering and is designed to have a low flow at a constant speed and very high pressure. This pump can inject fluids at a rate of $0.3 \mathrm{~mL} / \mathrm{min}$ to $5 \mathrm{~mL} / \mathrm{min}$ at $100 \mathrm{psi}$. The high pressure rating is essential for this application. In many occasions solids can form near the injection point of the reaction chamber causing the input tubes to become clogged. The high pressure forces any solids out of this area.

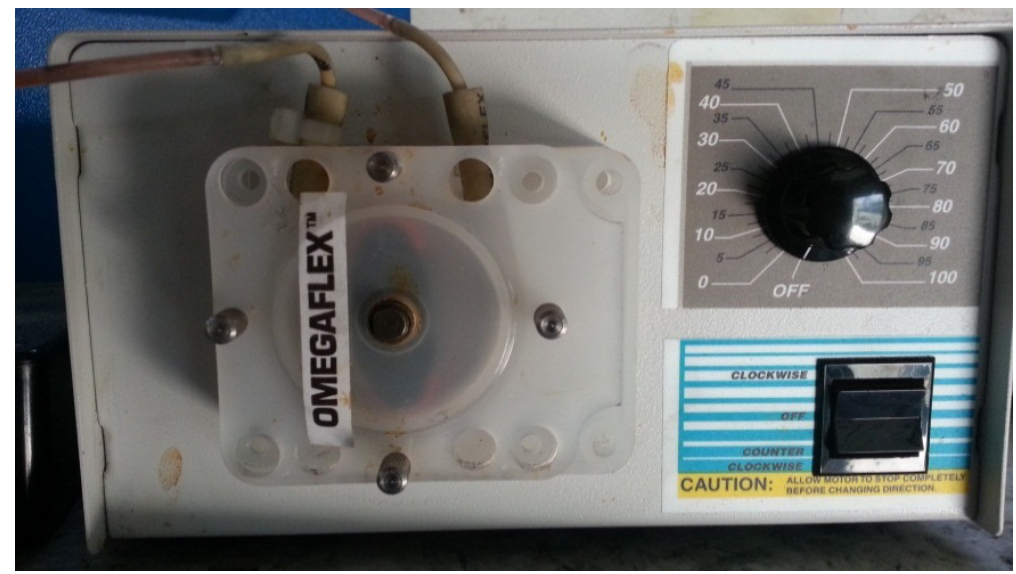

Figure 15 Peristaltic Pump 


\subsection{Gas Flow Controller}

The gas flow controllers are used to control the pressure and rate of injection of the gasses in and around the reaction chamber. The controller uses a 0 to 5 VDC input signal representing $0 \mathrm{~L} / \mathrm{min}$ to $20 \mathrm{~L} / \mathrm{min}$, respectively. In addition, the controllers also output a 0 to 5 VDC signal that is the true flow rate. This is a huge advantage over regular flow rate systems that only have an input. As is it possible to compare to the theoretical inputted value with the true flowing value, it is simple to see if there are any errors in the injection process. In addition, warning systems in the computer program indicate if there is a decrease in input pressure, possible congestion inside the injection tube, possible damage to the injection tube, or an empty supply tank.

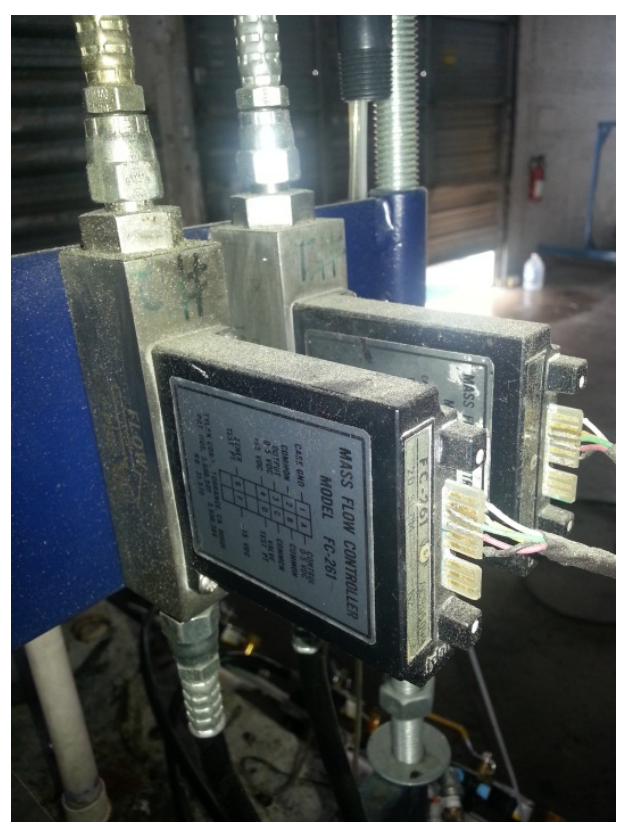

Figure 16 Gas Flow Controllers 


\subsection{Computer Program}

The computer program was designed and programmed using Labview and data acquisition boards. The program monitors the induction system, control flow rate, and warns of instability or an incorrect flow rate. Currently, the high-voltage system, peristaltic pump, and temperature are all manually controlled independently. In the near future it will be possible to wire all of the equipment and control them from a single computer.

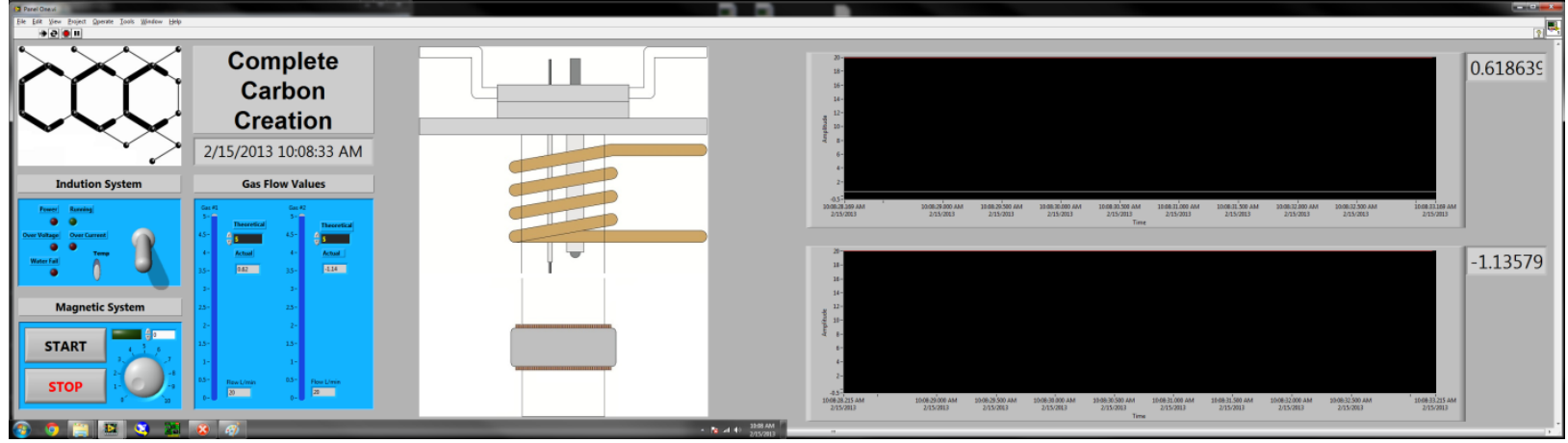

Figure 17 Computer Program; On the left side are the basic controls for the induction system, gas flow, and a few other parameters that were never installed; On the right there are two graphs that show the theoretical and actual flow of the gases for the last 60 seconds.

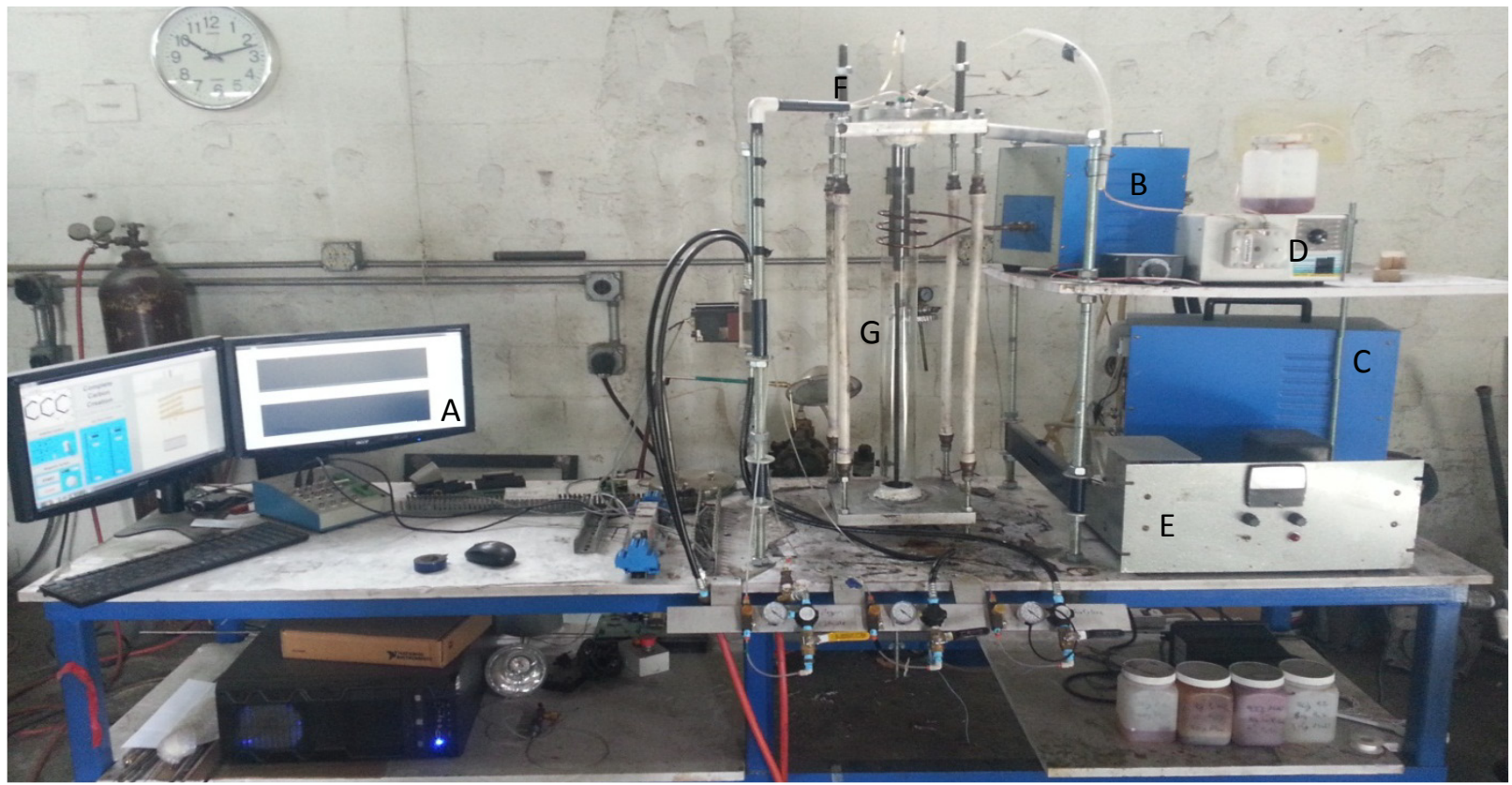

Figure 18 Entire Setup; A - Computer Program; B - Induction System Head; C Induction System Power Source; D - Peristaltic Pump; E - High Voltage System; F Injection Head; G - Cooling Area 


\section{Test Runs}

Throughout the trials, six situations were encountered and classified as: excess catalyst, excess acetylene, excess oxygen, lack of voltage, lack of induction, and lack of catalyst.

\subsection{Excess Catalyst}

Throughout this test, the flow rates, catalyst solution, induction power setting, and voltage setting were as below.

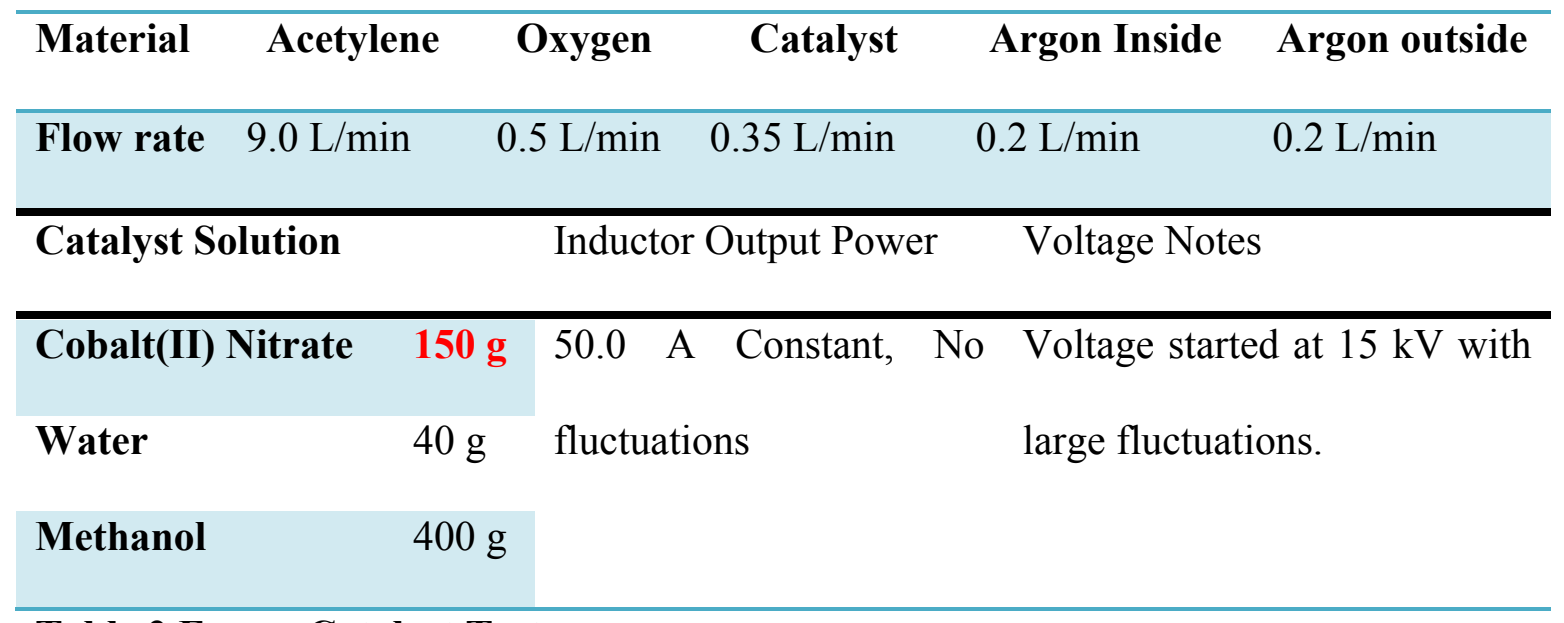

\section{Table 2 Excess Catalyst Test}

During this trial, the catalyst solution had an increased percentage of cobalt (II) nitrates. As the trial commenced, small traces of carbon nanotubes were produced. All flow rates were unchanged with no large fluctuations. The high-voltage supply, which started at $15 \mathrm{kV}$, was now reading $8 \mathrm{kV}$; this fluctuation was expected. Approximately one minute after starting the trial, the production of carbon nanotubes diminished, the flow rate of the acetylene and internal argon reduced, and the voltage, which was at $8 \mathrm{kV}$, had returned to $15 \mathrm{kV}$. The trial was terminated at this time. 
Upon inspection of the reaction chamber, a wall of what appeared to be compacted metallic dust was found, which an analysis showed to be cobalt. The injection and pyrolytic process were successful; however, the higher percentages of cobalt (II) nitrate in the catalyst solution caused excess cobalt to start depositing near the injection ports. As the injection process continued, the high temperatures fused the cobalt to the walls of the injection chamber and the pressure from the acetylene and argon injections compacted the newly added material.

\subsection{Excess Acetylene}

Throughout this test, the flow rates, catalyst solution, induction power setting, and voltage setting were as below.

\begin{tabular}{lcccll}
\hline Material & Acetylene & Oxygen & Catalyst & Argon Inside & Argon outside \\
\hline Flow rate & $\mathbf{1 8 . 0} \mathrm{L} / \mathrm{min}$ & $0.5 \mathrm{~L} / \mathrm{min}$ & $0.35 \mathrm{~L} / \mathrm{min}$ & $0.2 \mathrm{~L} / \mathrm{min}$ & $0.2 \mathrm{~L} / \mathrm{min}$ \\
\hline Catalyst Solution & & Inductor Output Power & Voltage Notes \\
\hline Cobalt(II) Nitrate & $40 \mathrm{~g}$ & $50.0 \mathrm{~A}$ & Constant, No & Voltage started at $15 \mathrm{kV}$ with \\
Water & $40 \mathrm{~g}$ & fluctuations & large fluctuations through the \\
Methanol & $400 \mathrm{~g}$ & & process and ending at $0 \mathrm{kV}$.
\end{tabular}

\section{Table 3 Excess Acetylene Test}

During this trial, the acetylene flow rate was much higher than normal. The trial commenced by producing small quantities of carbon nanotubes. Approximately 15 
seconds after commencement, the flow of all gasses had stabilized, and a large black smoke cloud started to come from the reaction chamber. Within the cloud of black gas there was still a small amount of solid material. The power supply was drastically fluctuating. In addition, it was possible to hear crackling noises, indicating an electrical arc. Approximately two minutes after the beginning of the trial, the entire quartz tube filled with the black gas, impeding all sight, and the power supply was reading $0 \mathrm{kV}$ with random crackling noises every few seconds. The test was stopped at this time; all injected materials were closed while the vacuum was left on. Within 30 seconds the inside had dissipated leaving the quartz tube clear.

In the collection chamber there were solids, liquids, and gasses. The solid material that was collected at the bottom had a very low percentage of carbon nanotubes. The fluid was extremely thick and had a distinct smell of kerosene or diesel. Finally, the gas had a yellow tint and a high density. The gasses settled at the bottom of the tank; however, all attempts to isolate the gas for analysis failed. The gasses, unlike the liquid, were extremely flammable, which suggests that it had a similar hydrogen-carbon make up as the original acetylene.

Upon further analysis, this trial was unbalanced in two sections. First, in the chemistry, the lack of oxygen allowed the carbon to rejoin with the hydrogen to create carbonated gas and liquid. The second was an electrical unbalance, or lack of amperage, meaning that some, but not all, carbon atoms would be manipulated into carbon nanotubes (this is explained in the "Equipment" section). 


\subsection{Excess Oxygen}

Through this test, the flow rates, catalyst solution, induction power setting, and voltage setting were as below.

\begin{tabular}{|c|c|c|c|c|c|c|}
\hline Material & \multicolumn{2}{|c|}{ Acetylene } & Oxygen & Catalyst & Argon Inside & Argon outside \\
\hline Flow rate & $9.0 \mathrm{~L} / \mathrm{m}$ & & $3 \mathrm{~L} / \mathrm{min}$ & $0.35 \mathrm{~L} / \mathrm{min}$ & $0.2 \mathrm{~L} / \mathrm{min}$ & $0.2 \mathrm{~L} / \mathrm{min}$ \\
\hline \multicolumn{3}{|c|}{ Catalyst Solution } & \multicolumn{2}{|c|}{ Inductor Output Power } & \multicolumn{2}{|c|}{ Voltage Notes } \\
\hline \multicolumn{3}{|c|}{ Cobalt(II) Nitrate } & 50.0 & Constant, & \multicolumn{2}{|c|}{ Voltage started at $15 \mathrm{kV}$ with } \\
\hline Water & & $40 \mathrm{~g}$ & \multicolumn{2}{|c|}{ fluctuations } & \multicolumn{2}{|l|}{ no change. } \\
\hline Methanol & \multicolumn{2}{|r|}{$400 \mathrm{~g}$} & & & & \\
\hline
\end{tabular}

Table 4 Excess Oxygen Test

During this trial, the oxygen flow rate was much higher than normal. As the trial initiated, a flame started to emerge from the reaction chamber. As the flow rates stabilized to their preset levels, the flame got larger; therefore, the trial was shut down almost immediately. This was an expected result. Oxyacetylene torches also use acetylene and oxygen with the end result being a high-temperature flame. 


\subsection{Without The HV Field}

Through this test, the flow rates, catalyst solution, induction power setting and voltage setting were as below.

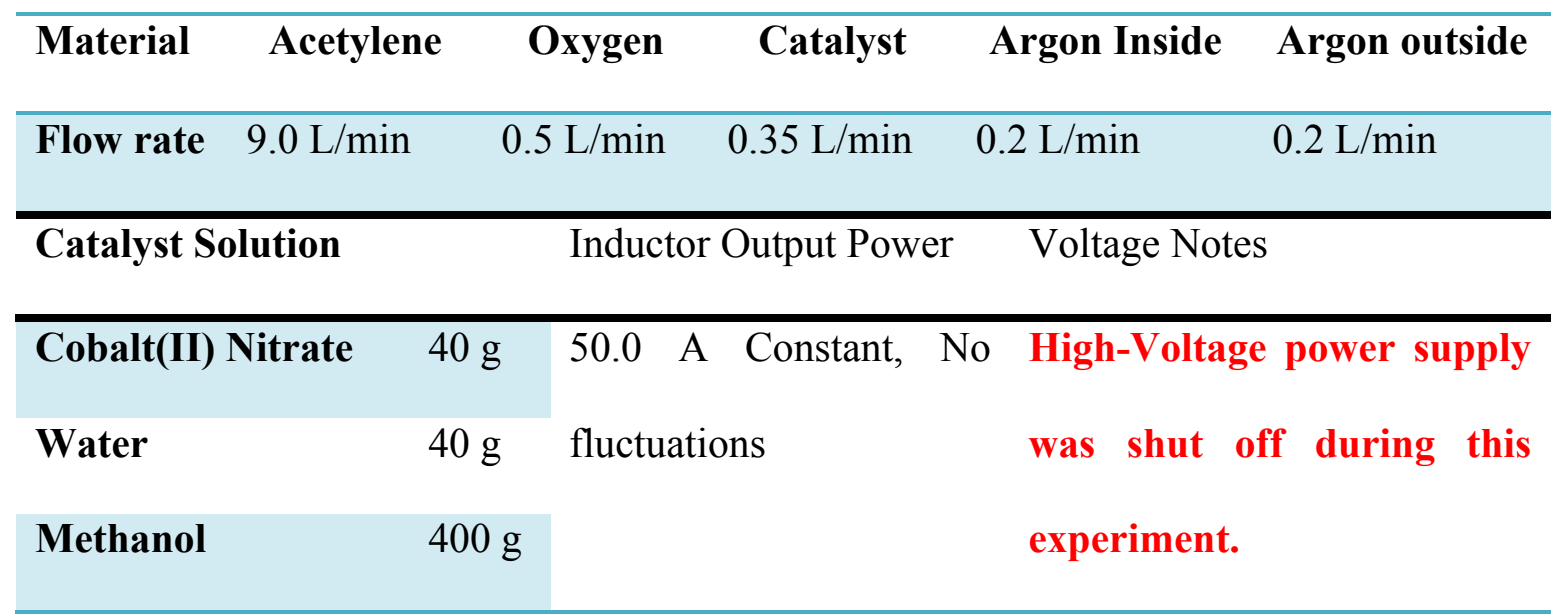

\section{Table 5 No High Voltage Test}

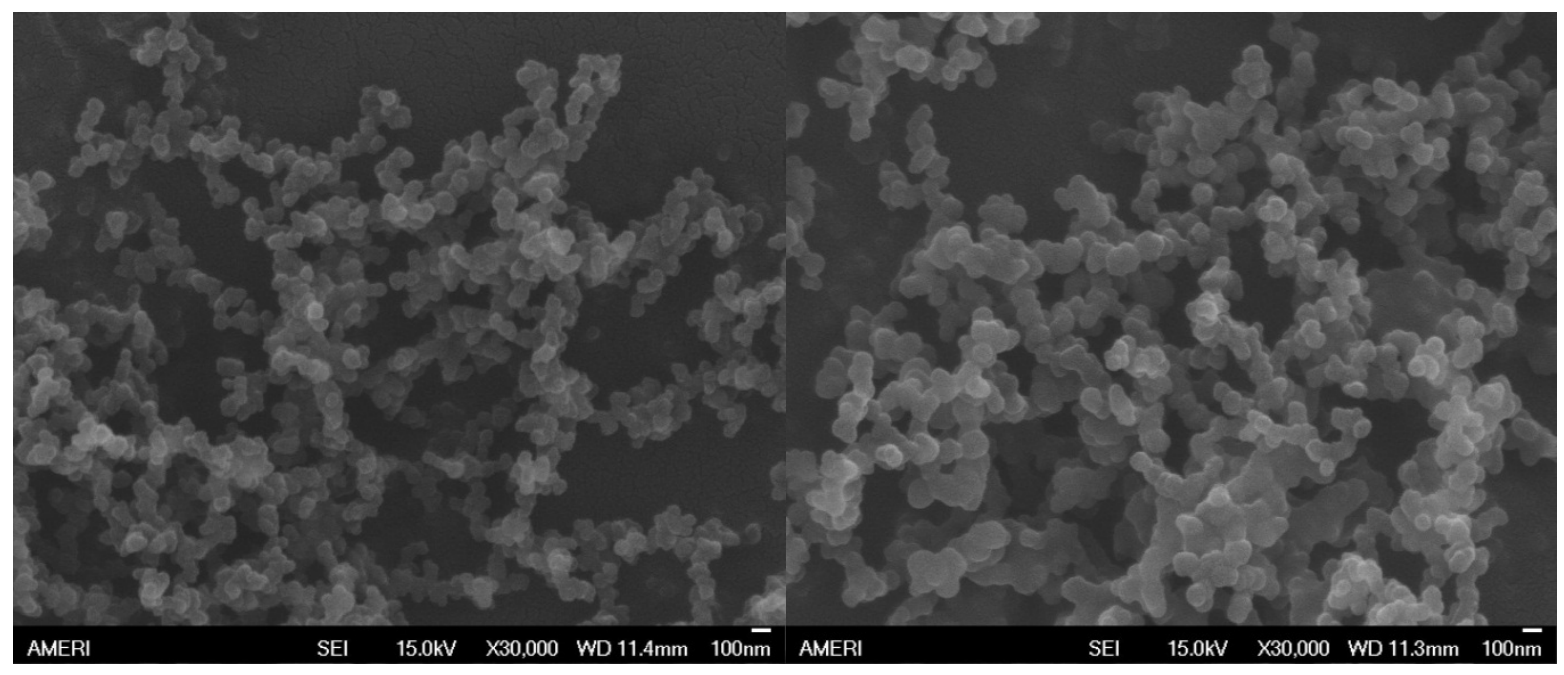

Figure 19 SEM of material produced without high voltage

During this trial, the high-voltage power supply was turned off. As the trial started, a large quantity of black smoke with solid particles formed from the exit of the reaction chamber. The trial was run for four minutes without any interruptions or changes 
in flow. The result, shown in Figure 19, shows a modified carbon structure that was labeled "carbon coral." One hypothesis about the formation of these structures is that with the absence of the high-voltage field, the carbon atoms are able to settle in the structure of their choosing; in this case, the structure was an elongated amorphous structure. The hypothesis as to why the structures are elongated is that the induction field creates minute currents within the reaction chamber, creating the same effect as the high voltage.

In various other tests without the high-voltage field, all flow rates were increased by $50 \%$ and resulted in similar structures. While the stoichiometry was correct, the current hypothesis is that the power supply could not produce sufficient amperage to manipulate such a large quantity of carbon atoms. 


\subsection{Without the Induction Field}

Throughout this test, the flow rates, catalyst solution, induction power setting, and voltage setting were as below.

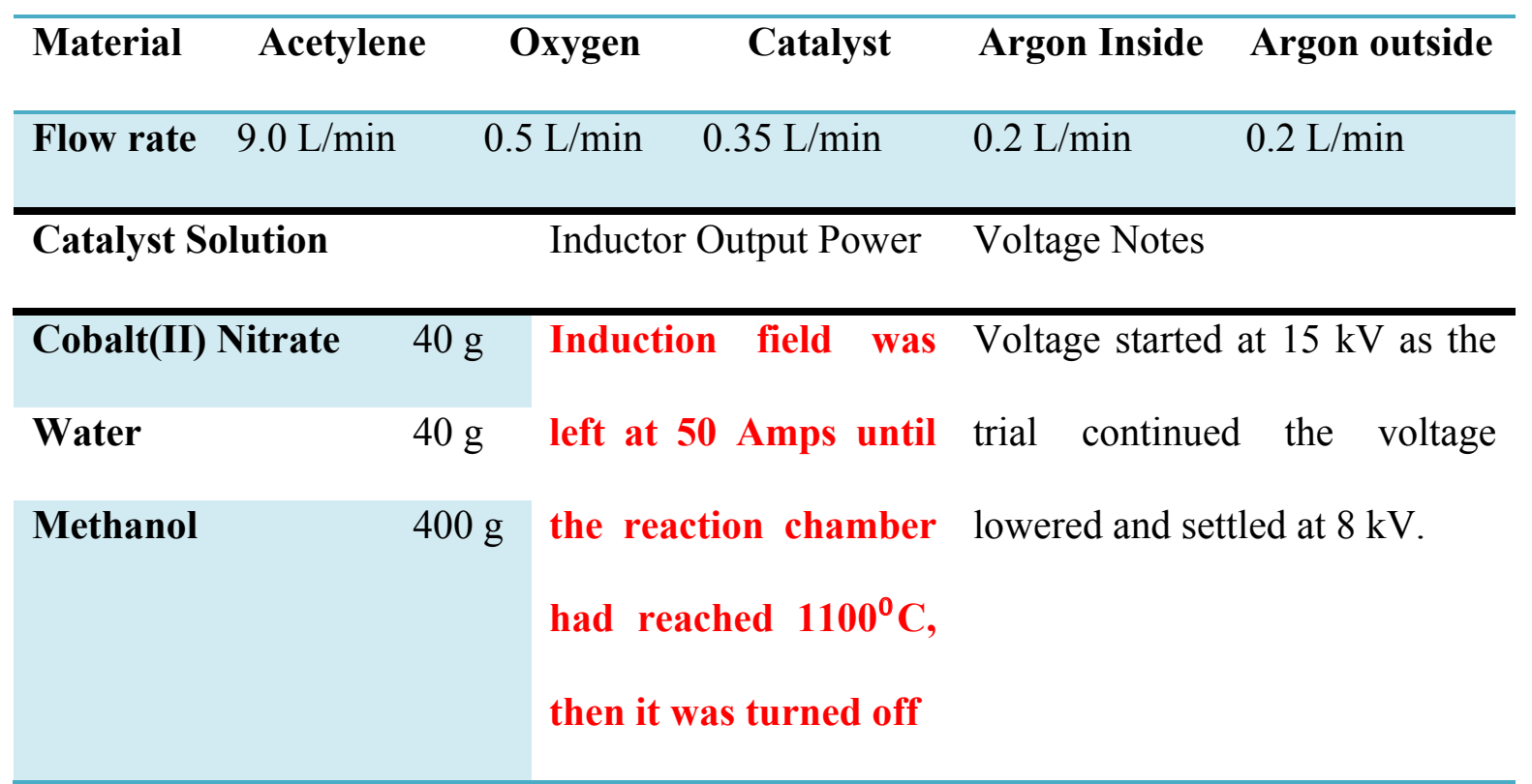

Table 6 No Induction Field Test

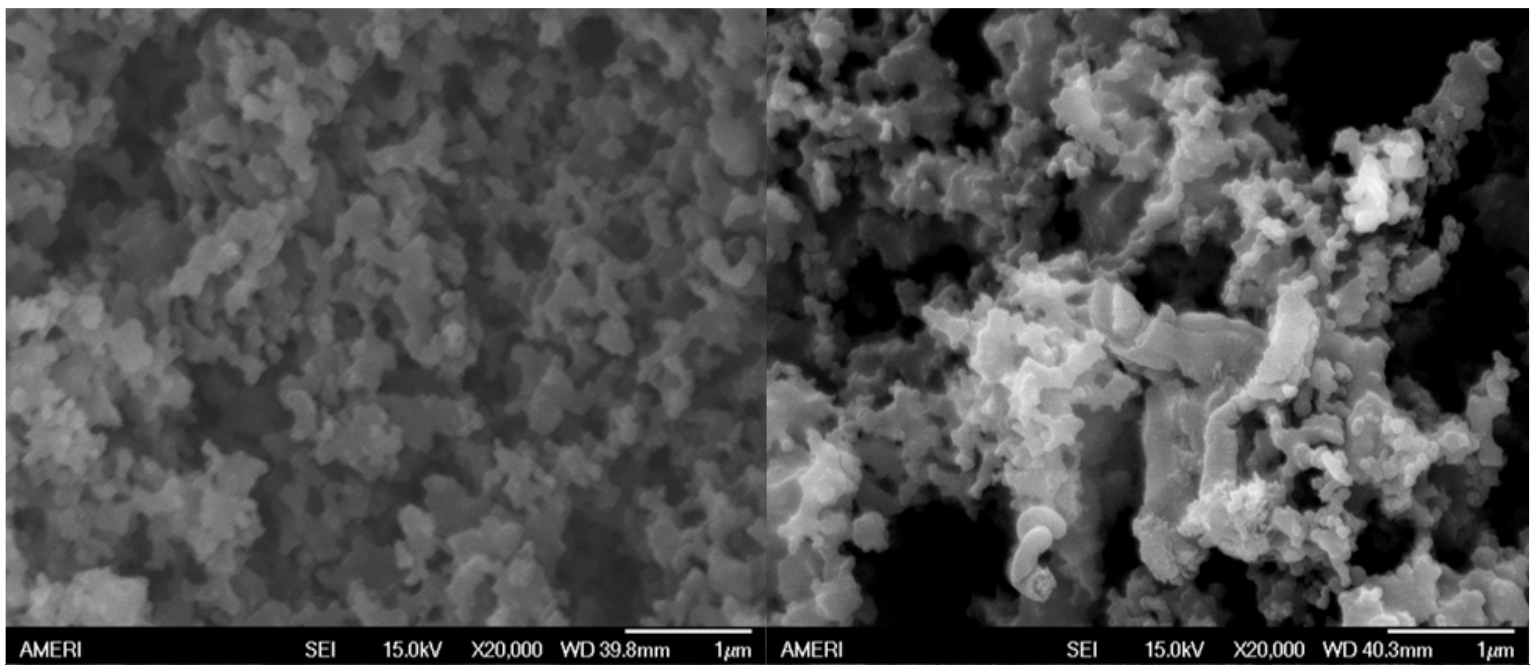

Figure 20 SEM of material produced without the induction field 
During this trial, the induction field was set to 50 amps until the reaction chamber reached operating temperatures, at which time it was turned off. As the induction system is the heat source for the pyrolytic process, this trial was limited to two minutes. Within those two minutes a small amount of solid black powder was produced. The material that was produced, shown in Figure 20, looked similar to animal scales. The formation of these scales seems to be linked to the absence of the magnetic field. While there is no evidence stating that there is a direct link between the magnetic field and the growth pattern, it is possible that an indirect link does exist since the field affects another component that affects the growth. One hypothesis that arose is that the high frequency of the induction field would violently move the metal catalyst's atoms in the high-voltage field, causing the scales to curve into tubes. Another hypothesis is that even though the reaction chamber has a very high thermal inertia, it cools down too quickly to finish the pyrolytic process. 


\subsection{Without the Metal Catalyst}

Throughout this test, the flow rates, catalyst solution, induction power setting, and voltage setting were as below.

\begin{tabular}{lccccc}
\hline Material & Acetylene & Oxygen & Catalyst & Argon Inside & Argon outside \\
\hline Flow rate & $9.0 \mathrm{~L} / \mathrm{min}$ & $0.5 \mathrm{~L} / \mathrm{min}$ & $\mathbf{0 . 0 0} \mathrm{L} / \mathrm{min}$ & $0.2 \mathrm{~L} / \mathrm{min}$ & $0.2 \mathrm{~L} / \mathrm{min}$ \\
\hline Catalyst Solution & & Inductor Output Power & Voltage Notes \\
\hline Cobalt(II) Nitrate & $40 \mathrm{~g}$ & 50.0 & A & Constant, No & Voltage started at $15 \mathrm{kV}$ with \\
Water & $40 \mathrm{~g}$ & fluctuations & no change. & \\
Methanol & $400 \mathrm{~g}$ & & & & \\
\hline
\end{tabular}

\section{Table 7 No Metal Catalyst Test}

During this trial, the catalyst solution injection system was turned off. As the trial started, a thick smoke began leaving the reaction chamber. After approximately two minutes with no solids being produced the test was stopped. Once the trial stopped, an extremely dense yellow gas and extremely dark oil-like substance were found sitting at the bottom of the reaction chamber. The yellow gas was extremely volatile while the oil seemed to be inert. One hypothesis that arose is that the pyrolytic processes happened successfully. The freed carbon, hydrogen, and cobalt atoms rejoined to create different carbonated gasses and liquids. The products were similar to high viscosity asphalt and vaporized diesel fuel. 


\section{Results and Discussion}

The creation of carbon nanotubes was a success. Several design flaws in the machine did not allow for continuous operation, limiting the length of each trial to approximately five minutes. The design flaws were in the design of the reaction chamber to evacuate all material (carbon nanotube or not), the method of collecting all of the material that was leaving the reaction chamber, and the rating of the power supply. Fixing these design flaws is vital before continuing testing.

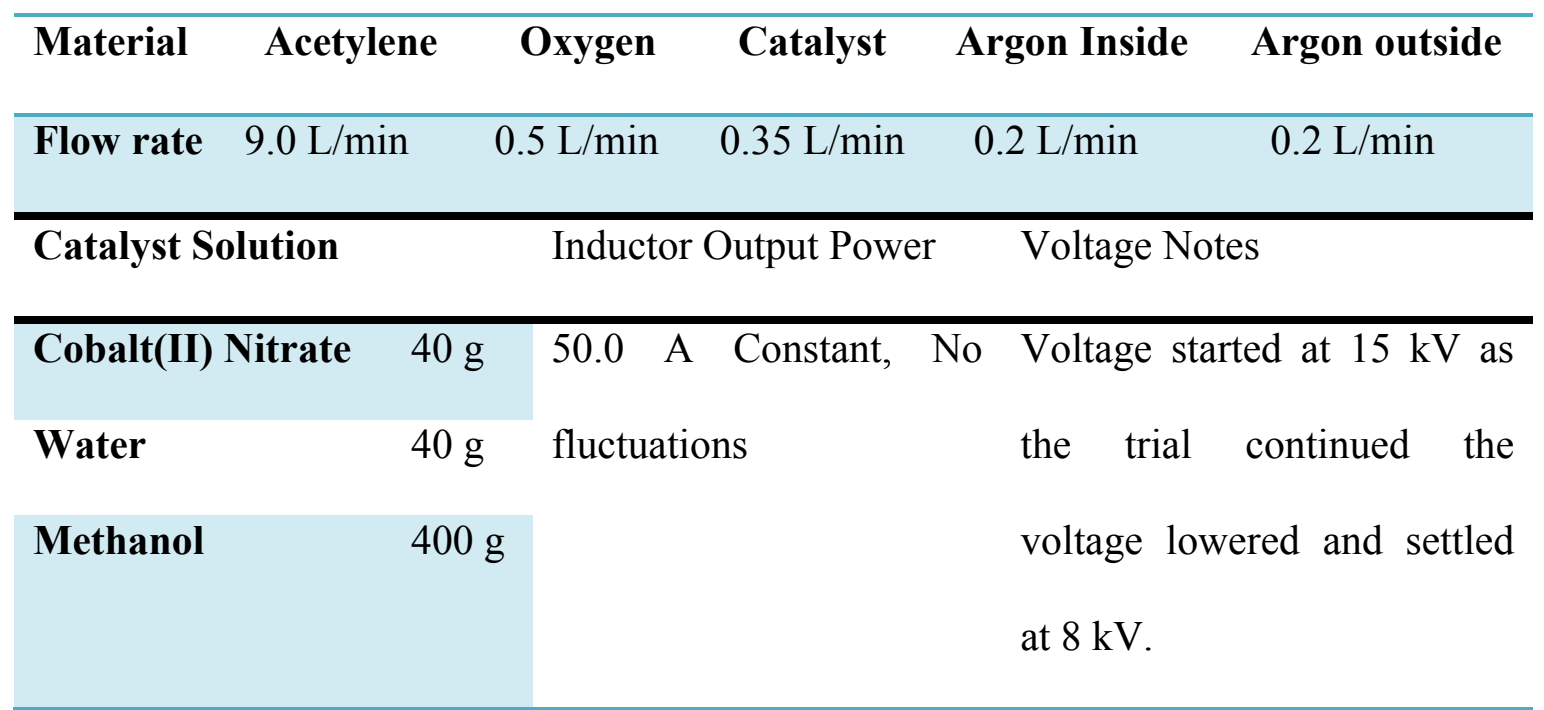

\section{Table 8 Optimized Test Results}

The values found in Table 8 are the most successful results. Within 15 seconds of the trial starting, small quantities of carbon nanotubes were being produced. The voltage, originally reading $15 \mathrm{kV}$, had started to drop and then stabilized at $8 \mathrm{kV}$. The process was continued for five minutes with an average production of 0.5 grams a minute. During this time, on the inside wall of the quartz tube condensation began to occur. This was a clear 
indication that the oxygen was reacting with the hydrogen from the acetylene and catalyst solution to create water.

Approximately five minutes after starting the trial, one of the following issues would occur: the vacuum vents would start to become obstructed due to a design flaw in the collection method, the reaction would start to move upwards inside the reaction chamber causing a stoppage at the injection point, or the material would collect at the exit of the reaction chamber causing a drastic drop in voltage. The material that was collected at the end was then analyzed using SEM, EDS, TEM, and a Raman spectrometer.

\subsection{Stoichiometry}

The three reactive agents that were injected were the methanol catalyst solution, acetylene, and oxygen. Carbon, cobalt, nitrogen, hydrogen, and oxygen were extracted from these three compounds. Throughout the process, condensation formed on the inside of the quartz tube and the carbon nanotubes deposited at the bottom of the reaction chamber had a very high humidity level. This is positive evidence that water was being produced. The carbon nanotubes were dried in an oven at $110^{\circ} \mathrm{C}$ before further analysis. The composition of the gasses that were extracted during the process was not tested. The stoichiometric results are as shown below. 


\begin{tabular}{lll}
\hline Input & & Output \\
\hline Methanol Catalyst Solution & $\left(\mathrm{Co}\left(\mathrm{NO}_{3}\right)_{2}+\mathrm{H}_{2} \mathrm{O}\right)+\mathrm{CH}_{3} \mathrm{OH}$ & $\mathrm{Co}+\mathrm{C}$ \\
\hline Acetylene & $\mathrm{C}_{2} \mathrm{H}_{2}$ & $\rightarrow \mathrm{H}_{2} \mathrm{O}$ \\
\hline Oxygen & $\mathrm{O}_{2}$ & $\rightarrow \mathrm{N}_{2}$ \\
\hline Argon & $\mathrm{Ar}$ & $\mathrm{Ar}$ \\
\hline
\end{tabular}

Table 9 Stoichiometry

\subsection{SEM Images}

The first test that is done to verify the existence of carbon nanotubes is placing a sample in a scanning electron microscope (SEM). Throughout the experiments, the SEM located at FIU's Advanced Materials Engineering Research Institute (AMERI) was used.

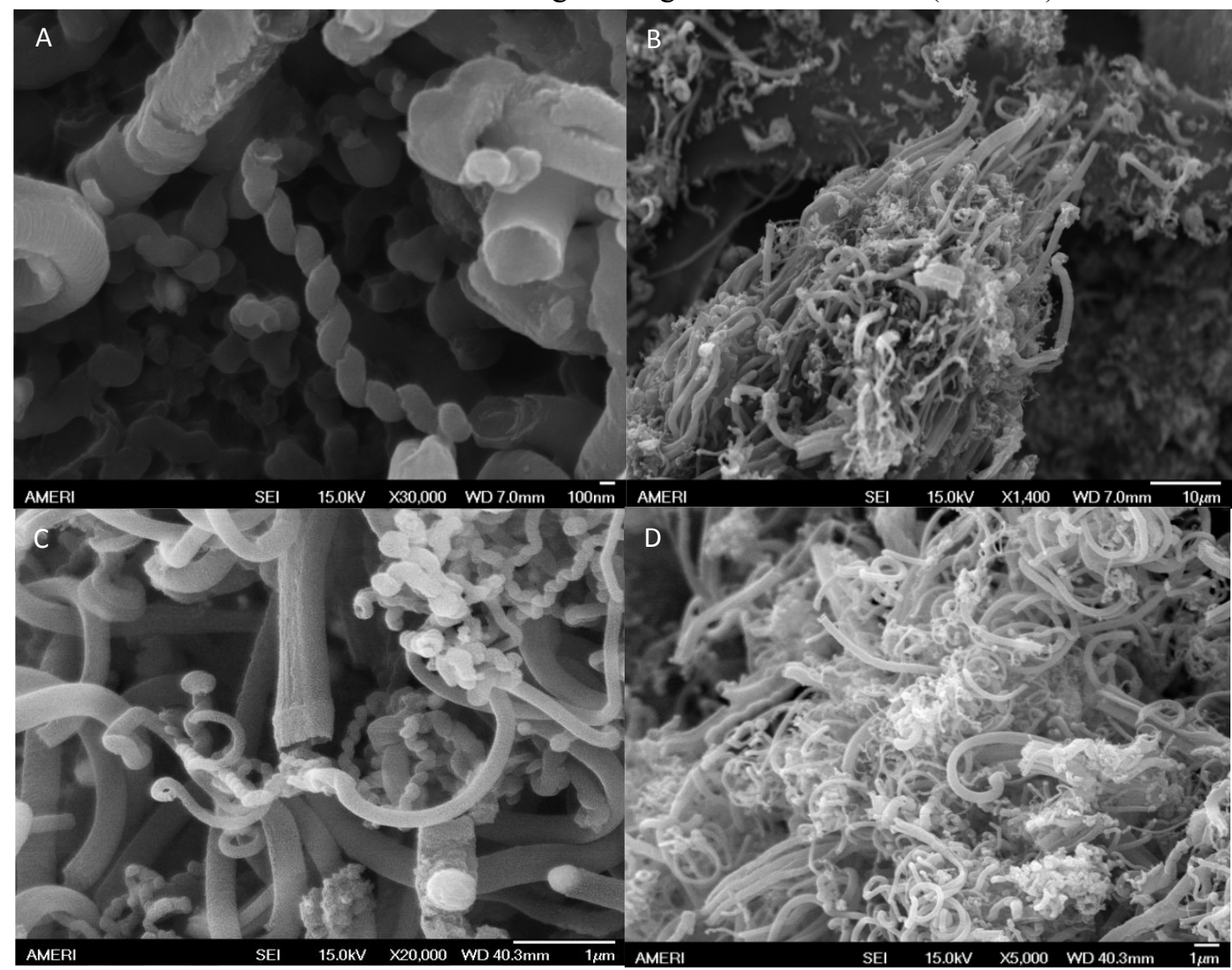

Figure 21 SEM of carbon nanotubes produced 
Upon closer analysis of the SEM images, all of the carbon nanotubes were found to have a curve or spiral feature which is unique to this process. The existing theory behind these features is that the induction field affected the growth. An induction field, in principle, is a high alternating frequency magnetic wave. A magnetic field that changes polarity 150,000 times a second would create dramatic forces on the cobalt atoms during the creation. The extremes of this affect can be seen in Figure 21-A where there are tubes that have been twisted beyond their limit and have begun to rip or tear. In Figure 21-A there is a tube in the middle which is open, showing that the larger tubes are hollow. Through all the pictures it is clear that the tubes are of various diameter, wall count, and length. The theory behind this phenomenon is the lack of control from the power supply. The power supply used during this process has a limiting voltage, not current. This causes the power supply to create an arc between the anode and cathode. Within this arc there is a large quantity of carbon atoms, some of which are already in tube form. Due to the large quantity of electrons, a larger conducting area has to be made. The end result is a large bundle of carbon nanotubes that are held together. 


\subsubsection{Energy - Dispersive X-ray Spectroscopy}

In addition to the images that were acquired above, the SEM used is equipped with an Energy - Dispersive X-ray Spectrometer (EDS). This process analyzes the characteristic $\mathrm{x}$-rays that are emitted from the sample, giving a chemical characterization of the sample.

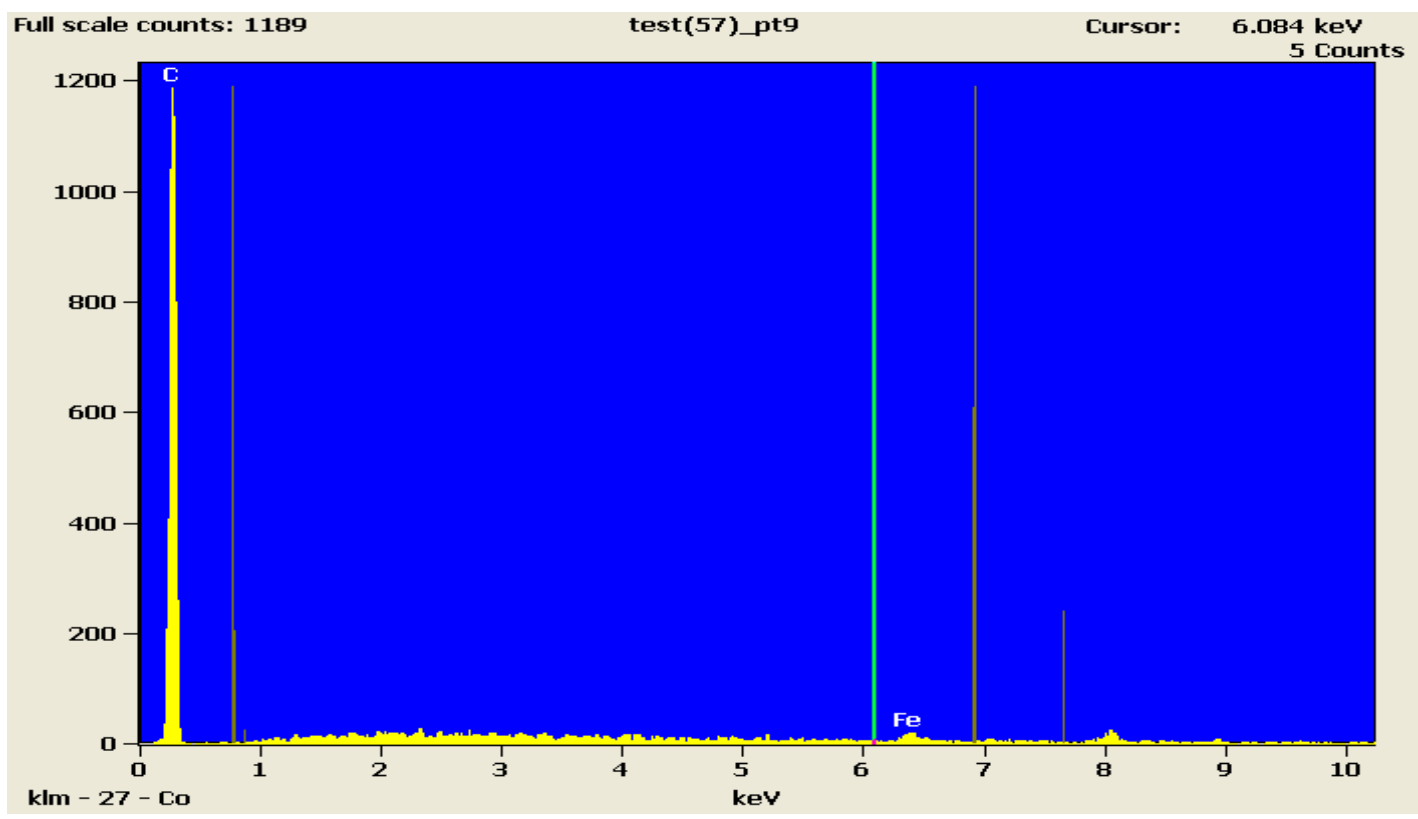

Figure 22 EDS of carbon nanotube sample produced

\begin{tabular}{|cccc|} 
Element Line & Element Weight\% & Weight\% Error & Atom\% \\
\hline C & 99.06 & \pm 0.89 & 99.80 \\
\hline Fe & 0.94 & & \\
\hline Total & 100.00 & & 0.20 \\
& & & \\
\hline
\end{tabular}

Table 10 Chemical composition of EDS sample shown in Figure 22 
The results show that carbon makes up $99.8 \%$ of the structure while the last $0.2 \%$ is made up of a metal. While the EDS readings show that the metal is iron $(\mathrm{Fe})$, the percentages are so low that it is not possible to decipher the exact metallic element. Through this test we were using cobalt as our doping agent, which has characteristic $\mathrm{x}$ rays in a similar location to iron. 


\subsection{TEM and Electron Diffraction pattern}

After the confirmation of carbon nanotubes by the SEM, we used TEM to analyze the internal structure and electron beam diffraction. TEM uses an electron beam to pass through a thin specimen, approximately $100 \mathrm{~nm}$ to $200 \mathrm{~nm}$ thick. The electrons react with the sample, are collected, and then form an image of the structure.

\subsubsection{Analysis of the Tubes}

Out of the three structures that were produced we are most interested in the tubes.

In Figure 23, we compare similar tube structures using SEM and TEM. The TEM shows a difference in coloring near the edge of each structure that signifies that the internal structure is hollow.

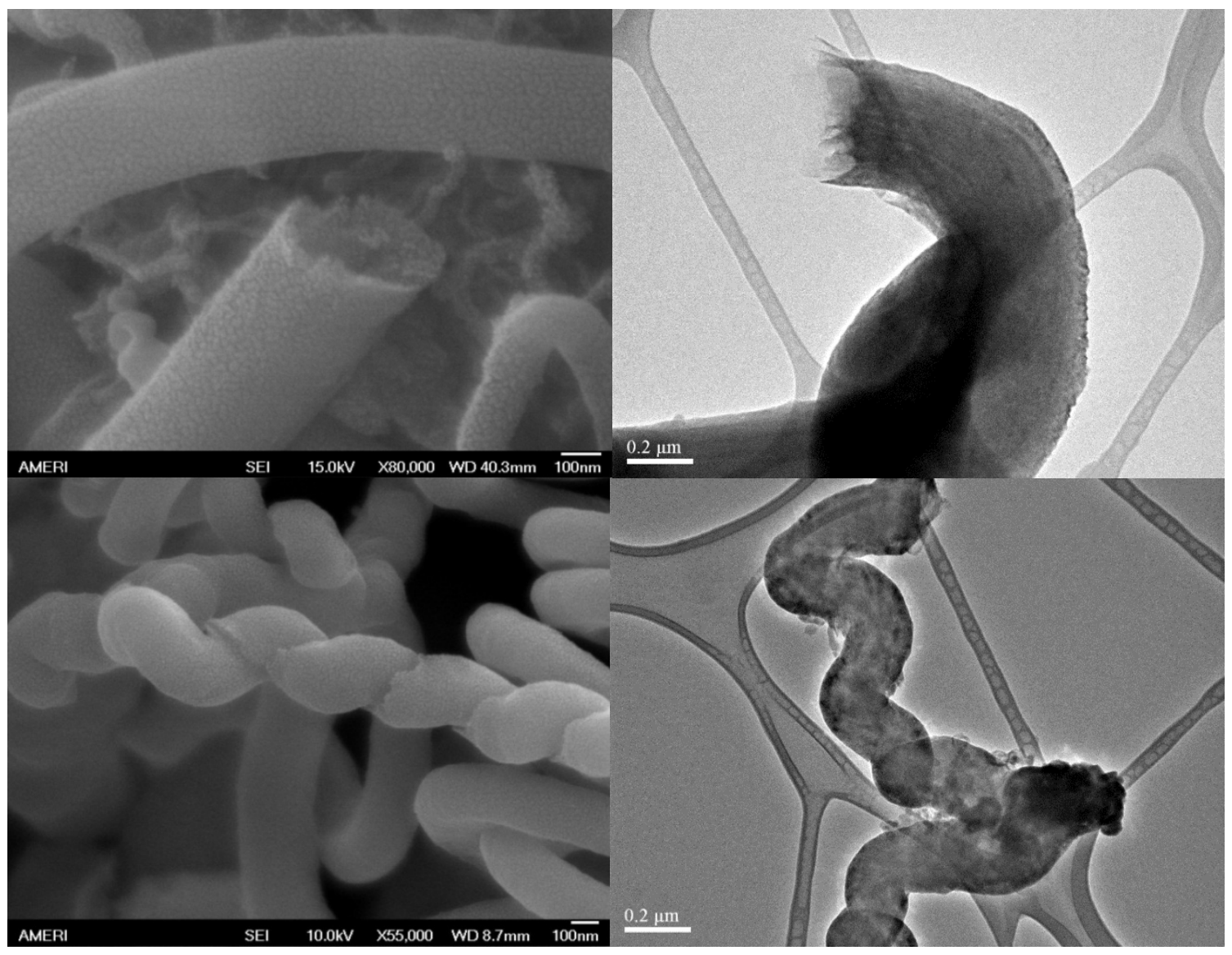

Figure 23 SEM and TEM images of similar structures, highlighting the hollow structure of the tubes. 
Another aspect that a TEM offers is the possibility of creating an electron backscatter diffraction pattern. Electron backscattering diffraction is a way to examine the crystallographic orientation of a material. The pattern shown in Figure 24 is that of the tube in Figure 23. After taking the picture we measure the distance from the center of the beam to each of the rings. The radius is then used in the equation below. Where $\mathrm{L}$ is our lens diameter, in this case $840 \mathrm{~mm}$, and $\lambda$ is the wavelength of the power that is being used, in this case $200 \mathrm{kV}$ is 0.025 angstroms. When comparing the results from the JCPDS card and the results from the TEM, the average error is about $2 \%$. This indicates that these tubes are in fact carbon nanotubes.

$$
D=L \lambda / r
$$

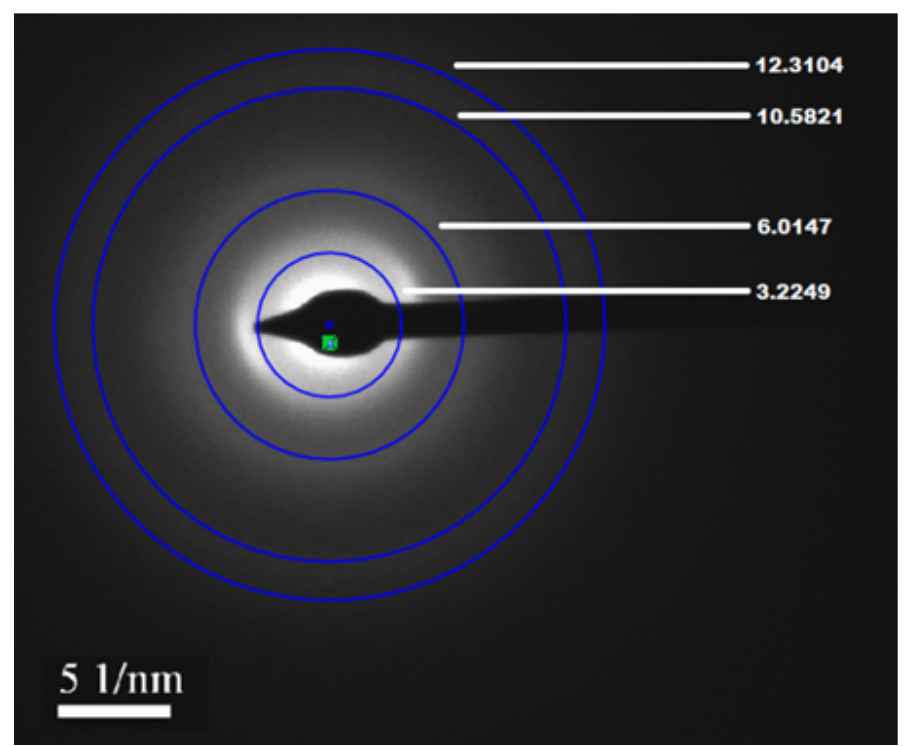

Figure 24 TEM Electron diffraction pattern for tube structures found in Figure 24

\begin{tabular}{lllll}
\hline Calculated & 6.9471 & 3.4348 & 2.1037 & 1.7177 \\
Measured & 6.93904 & 3.4973 & 1.9888 & 1.7059 \\
Error\% & 0.1160 & 1.8196 & 5.4597 & 0.6823
\end{tabular}

Table 11 Results for Electron Diffraction Pattern 


\subsubsection{Analysis of the Coral Structure}

The other structure that is found sporadically throughout the samples is the structure bellow, which was named "carbon coral." This structure was found predominantly when there was a lack of voltage (this can be seen in chapter 7.4). The electron beam diffraction in Figure 26 is of the TEM image in Figure 25. The average error is approximately $2.5 \%$. This signifies that the carbon coral is a carbon nanotube derived structure. A theory was formatted about these structures; the carbon nanotubes are wound up so tightly (as seen in Figure 24 lower left) that they break and rejoin into these structures.

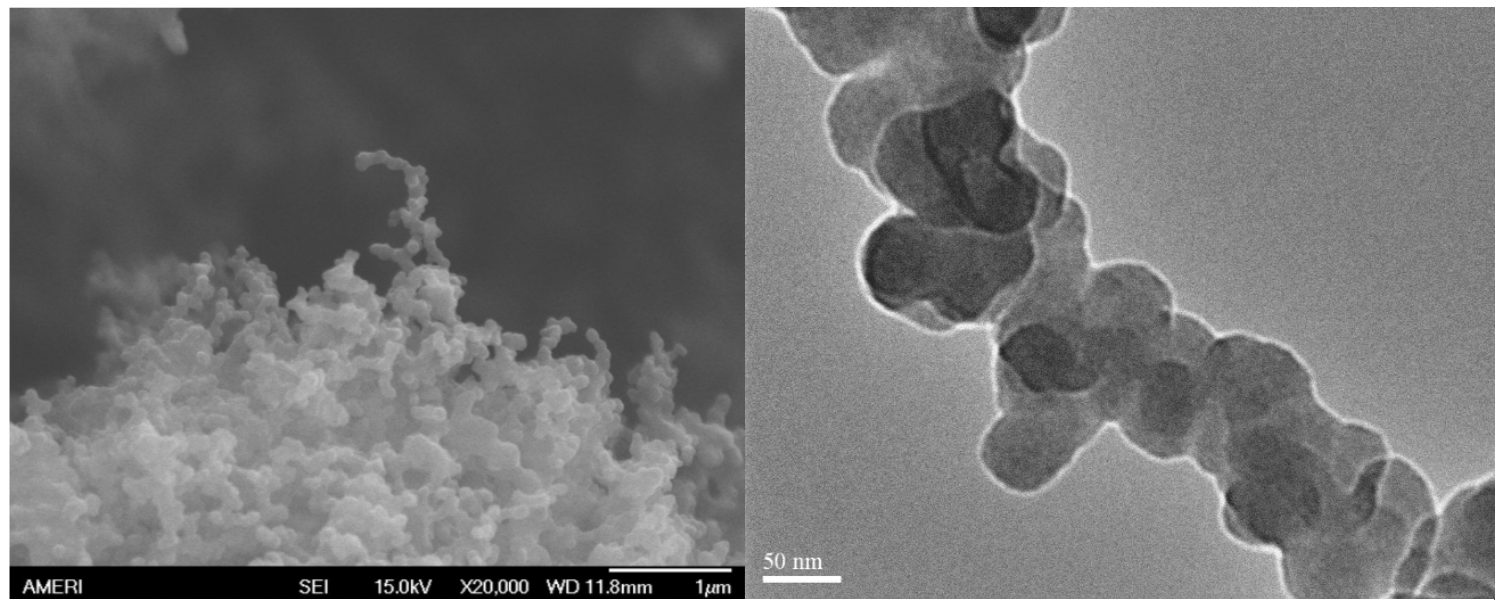

Figure 25 SEM and TEM of carbon coral

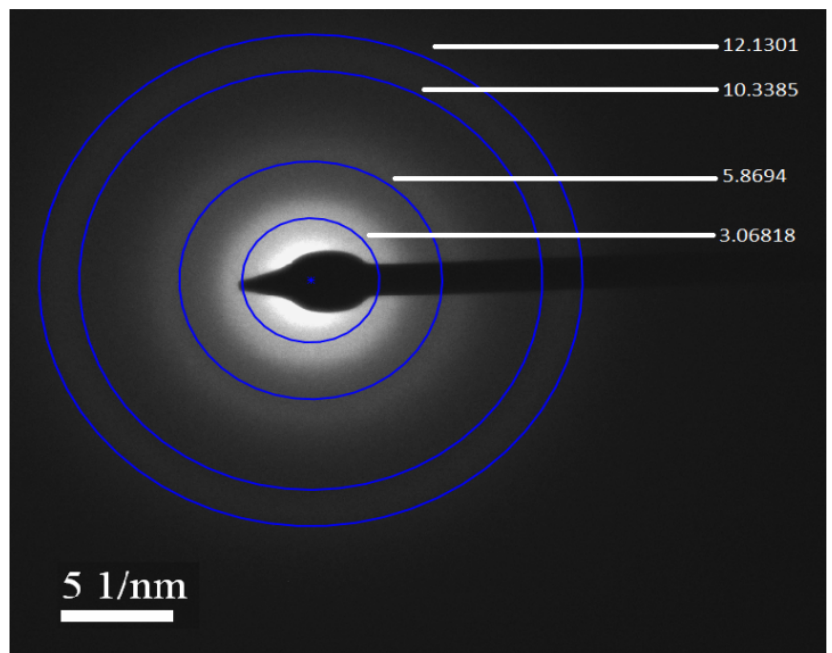

Figure 26 TEM electron diffraction pattern of coral structure found in Figure 24 


\begin{tabular}{lllll} 
Calculated & 6.9471 & 3.4348 & 2.1037 & 1.7177 \\
Measured & 6.8444 & 3.5779 & 2.0312 & 1.7312 \\
& & & & \\
Error\% & 1.4776 & 4.1668 & 3.4433 & 0.7906 \\
\hline
\end{tabular}

Table 12 Results for Electron Diffraction Pattern

Dr. Jianyang $\mathrm{Wu}$ showed a similar occurrence in a simulation in one of his papers [11]. The simulated nanotube underwent high torsion strength causing it to rip at a join. The carbon atoms that were exposed in the rip would join to their adjacent atoms causing a series of arm chairs that were interlinked. If this process were to happen enough the carbon coral would be produced.

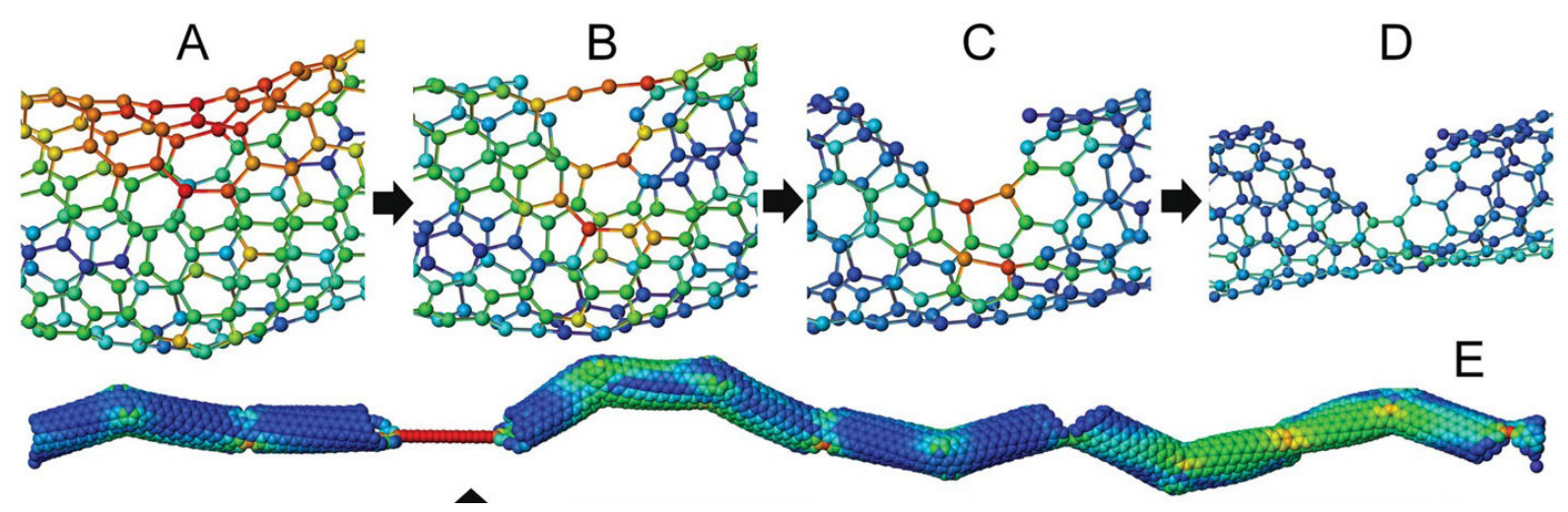

Figure 27 Dr. Jianyang Wu simulation of carbon nanotube going through stress [11] 


\subsubsection{Analysis of the Scales}

The final structure that is seen through the samples is the scale structure. This structure was most commonly found when the induction field was not present (this can be seen in Chapter 7.5). The electron diffraction beam in Figure 29 is of the TEM image in Figure 28. The electron diffraction shows a semi-crystalline carbon structure. These particles are found very rarely and in very low volume throughout the samples. The final objective is to reduce or completely eliminate these structures from anything that is produced.

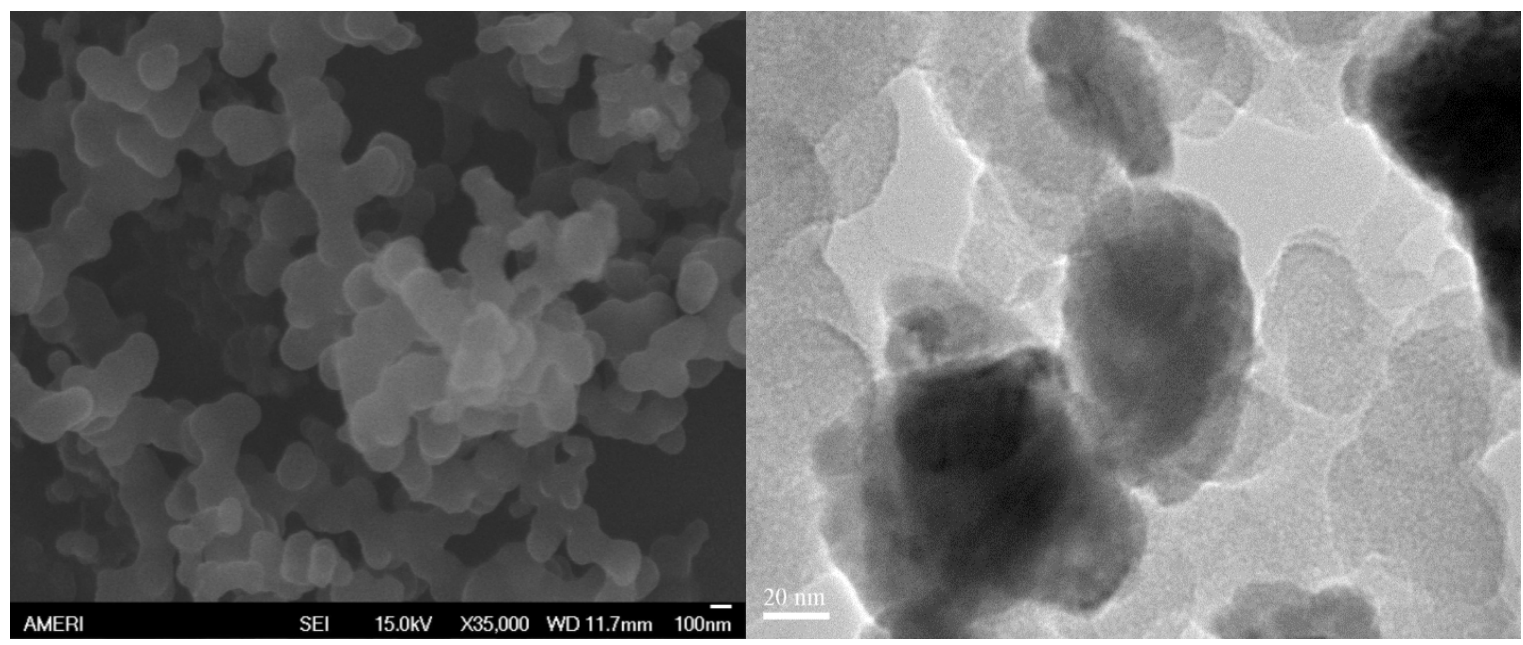

Figure 28 SEM and TEM of carbon scales

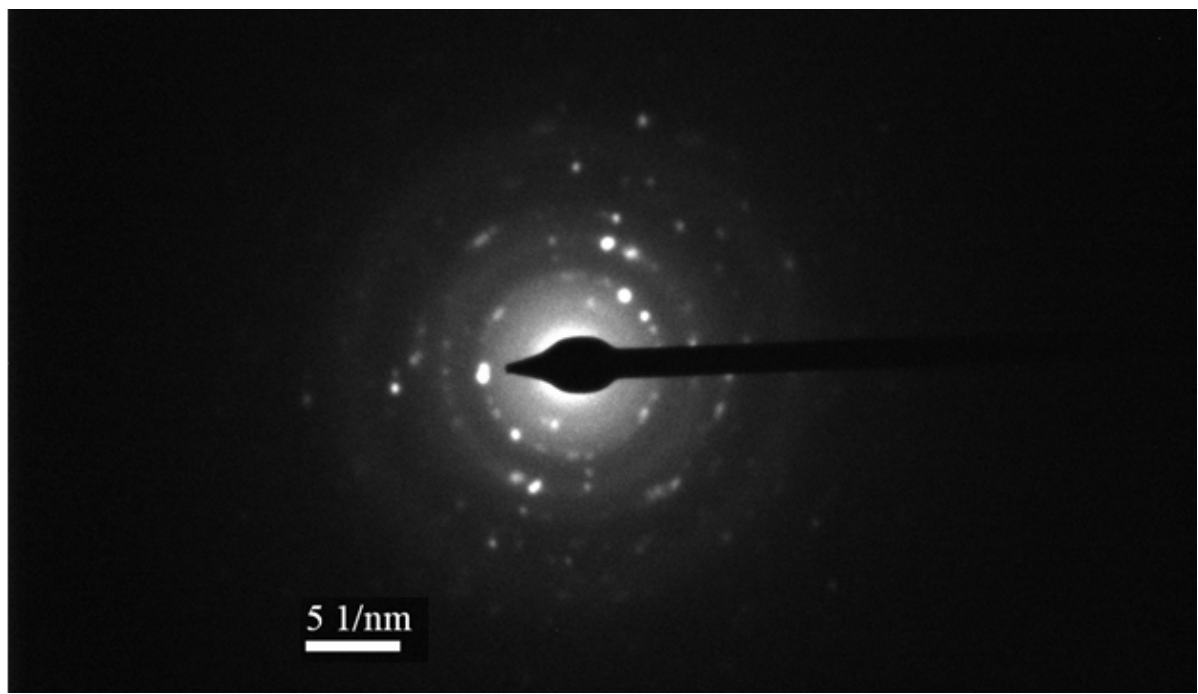

Figure 29 Electron diffraction pattern of carbon scale structure 


\subsection{Raman Graphs}

After confirming the existence of carbon nanotubes using the SEM and TEM, the samples were sent to Dr. Andriy Durygin at FIU's Center for the Study of Matter at Extreme Conditions (CeSMEC).The results are shown below and are compared to results found by other researchers in this field.
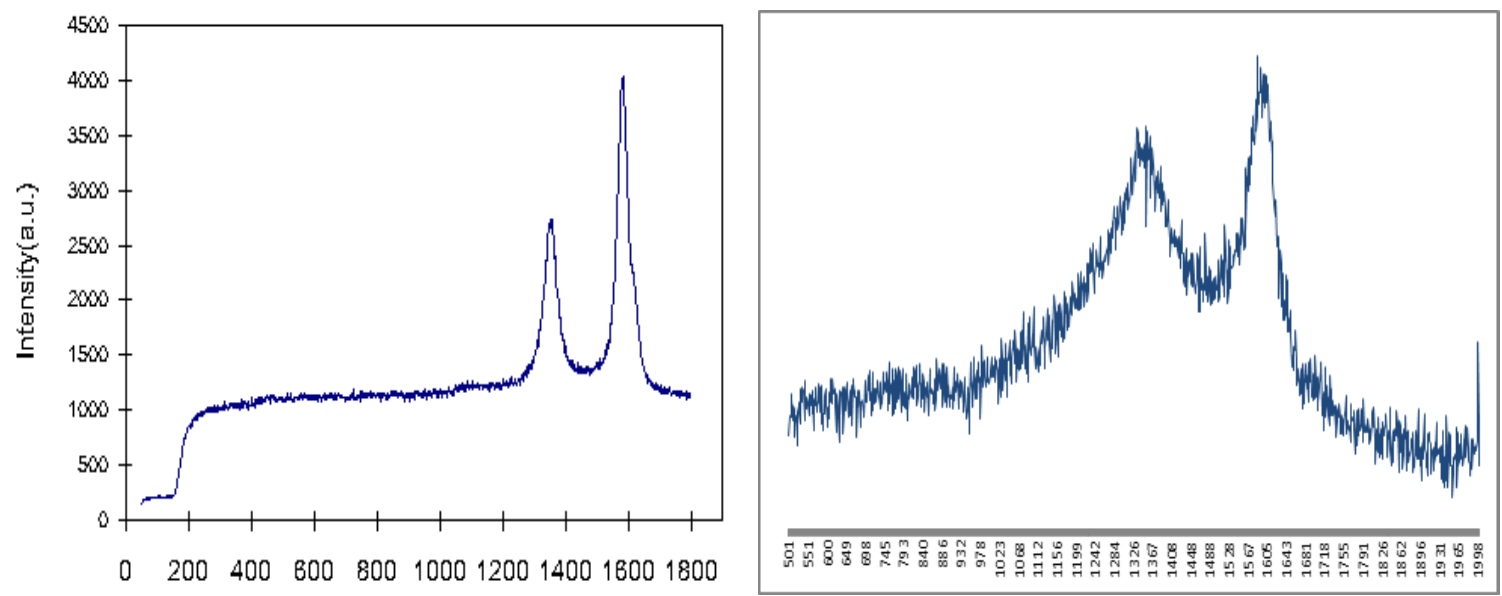

Figure 30 Raman Comparision of Multi-Walled Carbon Nanotubes [4]

The image to the left is a Raman spectroscopy courtesy of Cheaptubes.com. The most common features of a multi-walled carbon nanotube Raman spectroscopy are two dominating spikes around the 1350 and $15501 / \mathrm{cm}$ range. When comparing the finding of cheaptubes.com labs with the findings of this study, one can observe that there are spikes at the same ranges.

In addition to comparing the result with existing results, we can also measure the purity by measuring the relationship between the G-band peak and the D-band peak. These peaks can be found at $1350 \mathrm{~cm}^{-1}$ and $1580 \mathrm{~cm}^{-1}$ respectively. The multi-walled nanotubes had a purity of $99 \%$ while the single-walled showed a purity of $97.5 \%$. 


\subsection{Production Rate}

The use of carbon nanotubes in the mass market is currently limited due to the price and volume of production. Current CVD methods are capable of reaching 1 to 15 grams per hour. There are large companies that sell carbon nanotubes to universities and research centers, such as Nation Research Council Canada, which state that their production speed is two grams per minute. Throughout the trials we averaged approximately 0.5 grams per minute of production. While this rate is still below that of large institutes, I believe that with enough and time and the right components it will be possible to reach and even surpass the current production speed. 


\section{Conclusion and Future Work}

The production of carbon nanotubes was successful. Electrons can be used to force carbon atoms to settle in a predetermined formation. While proof of concept was a success, the design of the machine still needs to be perfected.

The design errors prohibited the extended operation and precise control of the multiple variables. The introduction of the computer program helped in controlling a limited number of variables; in the future the program will control the entire system and all variables. Having a program with this capacity would allow a more accurate control of all aspects of the machine, increase safety, and increase the production rate.

Advancements in the hardware are also necessary. The high-voltage system used was an older model; it could only limit the maximum voltage and had no over-current protection. Acquiring a high-voltage source which can vary maximum voltage and maximum amperage individually would increase the quality of the carbon nanotubes. A system that also includes over-current protection could protect the power supply and its users from potential damage. The current collection system could only work in intervals of 5 minutes. The objective of a future design would be for the production to run in a continuous form and include a method to sample the material being produced. Finally the reaction chamber must go through a refinement process to find the most efficient design for continuous production.

By improving the machine with a newer, more powerful, or more advanced version of the power supply, computer program, induction system, collection system, and reaction chamber, it will be possible to produce carbon nanotubes in a continuous form. 


\section{Works Cited}

[ 1 ] A. Montazeri, M. S.-T. (2010). Computational modeling of the transverseisotropic elastic properties of single-walled carbon nanotubes. Science Direct, 544551.

[ 2 ] Ando, M. K. (2010). Chemical Vapor Deposition of Carbon Nanotubes:. Journal of Nanoscience and Nanotechnology, 3739-3758.

[ 3 ] Berger, L. (2000). Dielectric Strengths Of Insulating Materials. CRC Press LLC.

[ 4 ] Cheap Tubes. (n.d.). Retrieved October 1, 2012, from Cheaptubes.com: http://www.cheaptubes.com/MWNTs.htm

[ 5 ] E.F. Kukovitsky, S. L. (2002). Correlation between metal catalyst particle size and carbon nanotube growth. Chemical Physics Letters, 497-503.

[ 6 ] Ebbesen, E. G. (1995). Mechanism of carbon nanotube formation in the arc discharge. Physical Review B, 2083-2089.

[ 7 ] Elmar C Fuchs, J. W. (2007). The floating water bridge. JOURNAL OF PHYSICS D: APPLIED PHYSICS, 6112-6114.

[ 8 ] Elmar C Fuchs, K. G. (2008). Dynamics of the floating water bridge. JOURNAL OF PHYSICS D: APPLIED PHYSICS.

[ 9 ] Iqbal, M. M. (2011). Production of Carbon Nanotubes by Different Routes-A Review. Journal of Encapsulation and Adsorption Sciences, 29-34.

[10 ] Jakob Woisetschlager, K. G. (2010). Experiments in a floating water bridge. Springer.

[11] Jianyang Wu, S. N. (November 11, 2013). Nanohinge-Induced Plasticity of Helical Carbon. Small, 3561 - 3566.

[ 12 ] Koziol, K. (2007). High-Performance Carbon Nanotube Fiber. Science Mag, 1892-1895.

[13 ] Lide, D. R. (2003 ). CRC Handbook of Chemistry and Physics, 84th Edition. Taylor \& Francis US.

[14 ] Meyyappan, M. (2004). Carbon Nanotubes: Science and Applications. Danvers, MA: CRC Press.

[ 15 ] Shoushan Fan, M. G. (1999). Self-Oriented Regular Arrays of Carbon Nanotubes and Their Field Emission Properties. Science Mag, 512.

[16 ] Wei Min Zhou, B. Y. (2006). Large-scale synthesis and characterization of SiC nanowires by high-frequency induction heating. Science Direct, 5143-5148. 
[ 17 ] Weiqiang Han, Y. B. (1999). Boron-doped carbon nanotubes prepared through a. Chemical Physics Letters, 368-373.

[18 ] WITec GmbH. (2013). Carbon Nanotubes Imaging - The Combination of Confocal Raman and Atomic Force Microscopy by WITec. AZoNano.

[19] Yellampalli, D. S. (2011). Carbon Nanotubes - Polymer Nanocomposites. Delhi, India: InTech. 


\section{Appendix}

JSCPS data sheet for carbon nanotubes

Status Primary QM: Indexed (I) Pressure/Temperature: Ambient Chemical Formula: C

Empirical Formula: C Weight \%: C100.00 Atomic \%: C100.00 Compound Name: Carbon Nanotubes

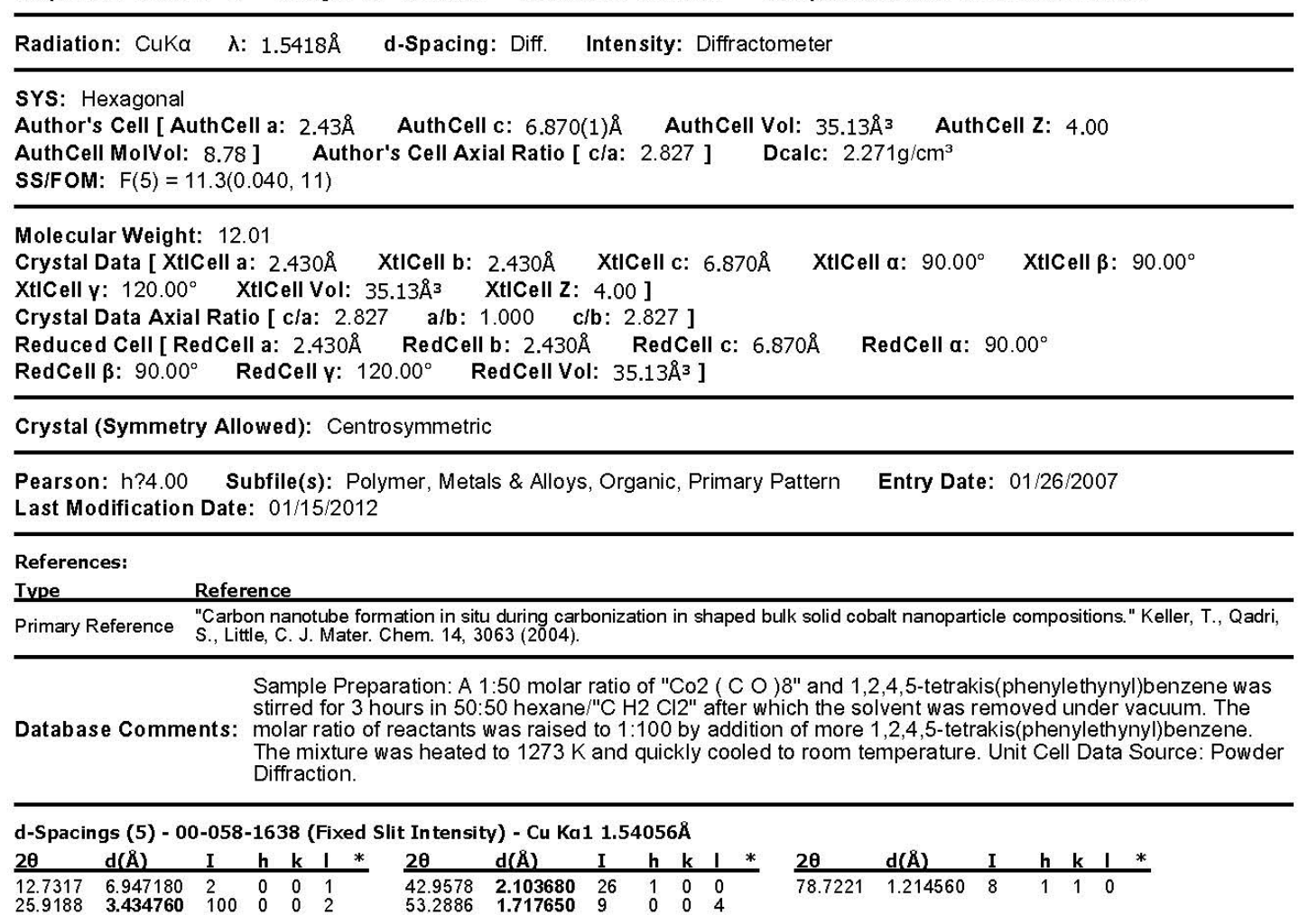




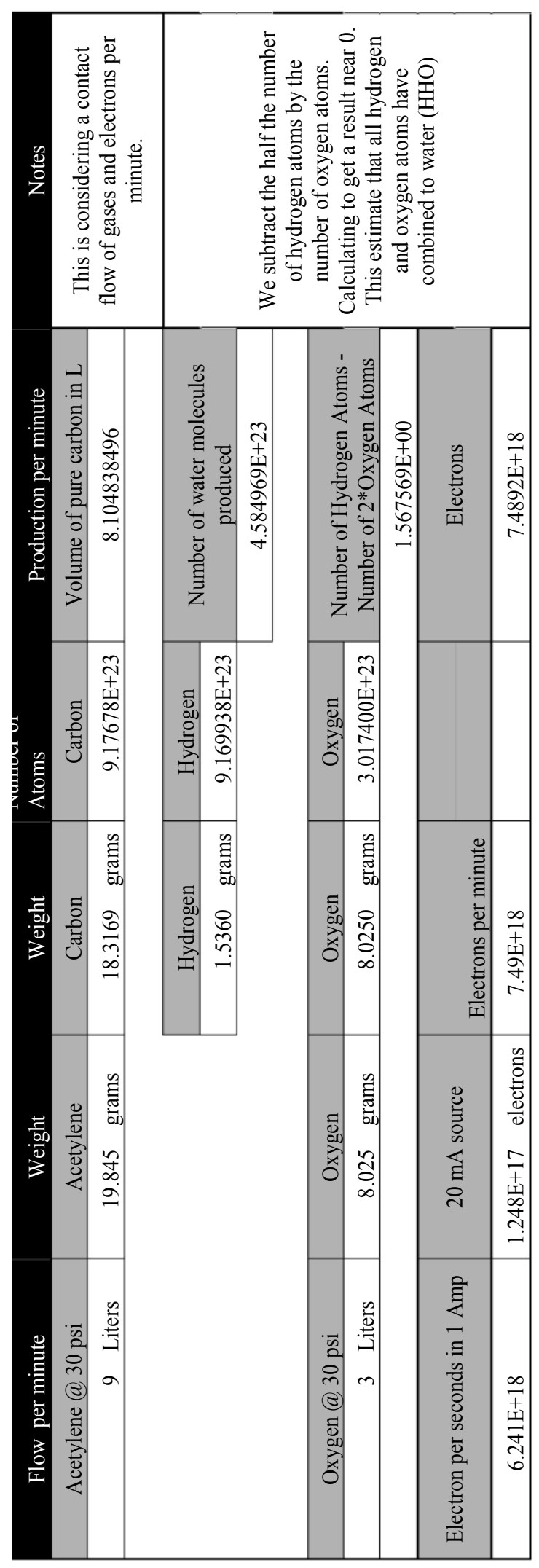

